\title{
Research Advances in Cardio-Cerebrovascular Diseases of Ligusticum chuanxiong Hort.
}

\author{
Dan $L i^{1}$, Yu Long ${ }^{1}$, Shuang $Y u^{1}$, Ai Shi ${ }^{1}$, Jinyan Wan ${ }^{1}$, Jing Wen ${ }^{1}$, Xiaoqiu $L i^{1}$, Songyu Liu ${ }^{1}$, \\ Yulu Zhang ${ }^{1}$, Nan $\mathrm{Li}^{1 *}$, Chuan Zheng ${ }^{1 *}$, Ming Yang ${ }^{2 *}$ and Lin Shen ${ }^{3}$ \\ ${ }^{1}$ State Key Laboratory of Southwestern Chinese Medicine Resources, Chengdu University of Traditional Chinese Medicine, \\ Chengdu, China, ${ }^{2}$ Key Laboratory of Modern Preparation of Traditional Chinese Medicine, Ministry of Education, Jiangxi \\ University of Traditional Chinese Medicine, Nanchang, China, ${ }^{3}$ Second Affiliated Hospital of Tianjin University of Traditional \\ Chinese Medicine, Tianjin, China
}

Cardio-cerebrovascular diseases (CVDs) are a serious threat to human health and account for $31 \%$ of global mortality. Ligusticum chuanxiong Hort. (CX) is derived from umbellifer plants. Its rhizome, leaves, and fibrous roots are similar in composition but have different contents. It has been used in Japanese, Korean, and other traditional medicine for over 2000 years. Currently, it is mostly cultivated and has high safety and low side effects. Due to the lack of a systematic summary of the efficacy of CX in the treatment of CVDs, this article describes the material basis, molecular mechanism, and clinical efficacy of CX, as well as its combined application in the treatment of CVDs, and has been summarized from the perspective of safety. In particular, the pharmacological effect of CX in the treatment of CVDs is highlighted from the point of view of its mechanism, and the complex mechanism network has been determined to improve the understanding of CX's multi-link and multitarget therapeutic effects, including anti-inflammatory, antioxidant, and endothelial cells. This article offers a new and modern perspective on the impact of CX on CVDs.

Keywords: Ligusticum chuanxiong Hort., cardio-cerebrovascular diseases, material basis, molecular mechanism, clinical efficacy

\section{INTRODUCTION}

Cardio-cerebrovascular diseases (CVDs) are the general name of cardiovascular and cerebrovascular diseases (Liu et al., 2021). They generally refer to the ischemic or hemorrhagic diseases of the heart, brain, and the whole body caused by hyperlipidemia, blood viscosity, atherosclerosis (AS), hypertension, etc. These include coronary heart disease (CHD), myocardial infarction, angina pectoris, coronary artery insufficiency, aortic AS, and other cardiovascular diseases, as well as ischemic stroke, hemorrhagic stroke, transient cerebral ischemia and other cerebrovascular diseases (Qin, 2020). CVDs can occur alone, but often exist at the same time in different degrees. CVDs is a common and serious threat to human health, with the characteristics of high morbidity, high disability rate, high recurrence rate, and high mortality. More than $31 \%$ of deaths worldwide are attributable to cardiovascular diseases, and more than any the other causes of death, this is the main cause of incidence rate and mortality rate in developing and developed countries (Stephanieh and Sarahh, 2020). The burden of global CVDs is increasing day by day, which has become a major public health problem. At present, there are more than 290 million patients with CVDs in China, accounting for 42.5 and $44.6 \%$ of the deaths in urban and rural areas (Zhou et al., 2019a). More than $80 \%$ of the cardiovascular disease burden could be attributed to known modifiable risk factors such as hypertension, dietary risks, high low-density lipoprotein cholesterol, and impaired kidney function 
(Paoloa et al., 2020). Hypertension, high cholesterol, and diabetes are the three major risk factors for CVDs, among which hypertension is the primary factor (Wang, 2016).

As we enter a golden age of drug discovery based on natural products, the growing interest in natural products has led to the discovery of new chemical entities for the treatment of various human diseases in the past decades. Natural drugs extracted from herbal medicines are valuable sources of chemical entities and provide important ways to discover new drugs. Complementary and alternative medicine (CAM) can be used to maintain human health for a long time because of less side effects. In addition, an increasing number of patients with CVDs have resorted to the use of CAM, which shows a great application prospect and scope of exploration.

At present, in the exploration of natural drugs for the treatment of CVDs, including Ligusticum chuanxiong Hort. (Chuanxiong, CX) (Wang et al., 2018b), Paeonia veitchii Lynch. (Chishao, CS) (Ke et al., 2017), Carthamus tinctorius L. (Honghua, HH) (Jin et al., 2016), Salvia miltiorrhiza Bunge (Danshen, DS) (Lim et al., 2017), Panax notoginseng (Sanqi, SQ) (Fan et al., 2016), Prunus persica (L.) Batsch (Taoren, TR) (Li et al., 2020a), Leonurus heterophyllus Sweet (Yimucao, YMC) (Liu et al., 2019a), Curcuma zedoaria Roscoe (Ezhu, EZ) (Wu et al., 2019), etc., it has been found that they play a certain role in hemorheology (Wang et al., 2011), hemodynamics, platelet function (Chen et al., 2020), anticoagulation, antithrombotic (Zhou et al., 2016) and microcirculation functions, regulation of blood lipids (Xu et al., 2019), dilation of blood vessels (Yang et al., 2020a), regulation of energy metabolism (Ke et al., 2017), and other aspects. The above problems are often accompanied by the course of CVDs. These drugs focus on the whole in the prevention and treatment of complex diseases such as hypertension, showing the advantages of "multi-link and multi-target." As one of the most frequently used drugs, CX can play its role in CVDs by expanding blood vessels and reducing the release of inflammatory mediators (He et al., 2018).

Evidence in the published literature suggests that CX is a herb with great potential to reduce the risk of CVDs and is already widely used clinically. Because CX has received good feedback in the treatment of CVDs, but there is no systematic summary of it, it is difficult to provide concise and clear reference significance for subsequent research and development. The purpose of this review is to summarize the current commonly used CVD drugs, and it has been found that CX has a huge competitive advantage in this aspect. Under the premise that the molecular mechanism of CX is still unclear, the material basis, pharmacological action, and clinical data of the cardiovascular and cerebrovascular aspects of CX are used as a support to provide a state-of-the-art overview of the chemistry and pharmacology about this valuable plant species and explore new perspectives and outline future challenges.

\section{CHARACTERISTICS OF LIGUSTICUM CHUANXIONG HORT.}

Ligusticum chuanxiong Hort. (Chuanxiong), also known as Ligusticum wallichii Franchat, belongs to Angiospermae, family
Umbelliferae, Ligusticum. It is a perennial herb with welldeveloped rhizomes and irregular nodules. The stem is upright, with vertical and longitudinal lines, many branches in the upper part, and the lower stem nodes expand into a disk shape. The lower part of the stem is petiolate, and the base expands into a sheath. Leaves are oval triangular, $12-15 \mathrm{~cm}$ long, and $10-15 \mathrm{~cm}$ wide, with $3-4$ pinnate lobes. Compound umbellate catkin terminal or lateral seen (Song, 2015). It is cultivated in Sichuan, Guizhou, Yunnan, Guangxi, and other places in China, and its cultivation history can be traced back to 1,500 years ago (Yin, 2013). In addition, according to different producing areas, it can be divided into "Chuanxiong (CX)" produced in Sichuan, "Yunxiong (YX)" produced in Yunnan and Guizhou, "Dongxiong (DX)" produced in the East, and "Fuxiong (FX)" produced in the northeast (Liu, 2020).

As a natural drug, CX was introduced into Europe through Arabia in the 10th century. At present, it is used in more than 20 countries and regions and has become one of the important drug resources in the world, with Japan and South Korea as the main export places (Ma et al., 2001; Li and Yu, 2020). It is known as "Senkyu" (Shizu et al., 2012) and "Tousenkyu” (Yi et al., 2006) in Japan, "chungung" (Rhyu et al., 2004) in South Korea, "Ligusticum chuanxiong Hort." (Lai, 2014) in Thailand, and "Szechuan lovage root" (Li et al., 2012) in Britain.

CX has always been used as medicine for its dry roots, but in recent years, it has been found that the stems, leaves, and fibrous roots of CX also have medicinal value. Compared with the rhizomes, only the content is different (Jiang et al., 2008). In the Bencao Huiyan, the aboveground part of CX is called "Mi Wu," accounting for $75 \%$ of the fresh weight of the whole plant (Jiang et al., 2008; Tang et al., 2021). At the same time, CX is also one of the drugs that can be used for health food announced by the Ministry of Health of China in 2017 (Yu, 2017). In addition, CX is widely used in health-care products, food, cosmetics, and other fields. Its tender stems and leaves can be eaten as vegetables, and its rhizomes can also be stewed with beef and mutton for use (Yang et al., 2013). It has the characteristics of strong safety and wide application fields (Wen et al., 2019).

CX has been used by Chinese medicinal physicians for more than 2,000 years (Shan and Hao, 2011); its pharmacological effect was first mentioned in the Shen Nong Ben Cao Jing (a compilation of information regarding Chinese herbs dating back to $2800 \mathrm{BC}$ ) (Ran et al., 2011). It has therapeutic effects on the cardiovascular and cerebrovascular system, liver and kidney system, nervous system, respiratory system, urinary system, and many other systems (Zhang et al., 2020b). CX is widely used in CVDs, which provides a certain theoretical basis for solving the problem of high global mortality and disability (Figure 1). It is an effective drug for the treatment of CVDs. Moreover, CX is widely cultivated and inexpensive. Strengthening its application and development is conducive to reducing the economic burden of patients with CVDs.

\section{PHARMACODYNAMIC SUBSTANCE BASIS OF LIGUSTICUM CHUANXIONG HORT.}

Up to now, more than 263 substances have been isolated from different parts (rhizomes, fibrous roots, and aboveground parts) 


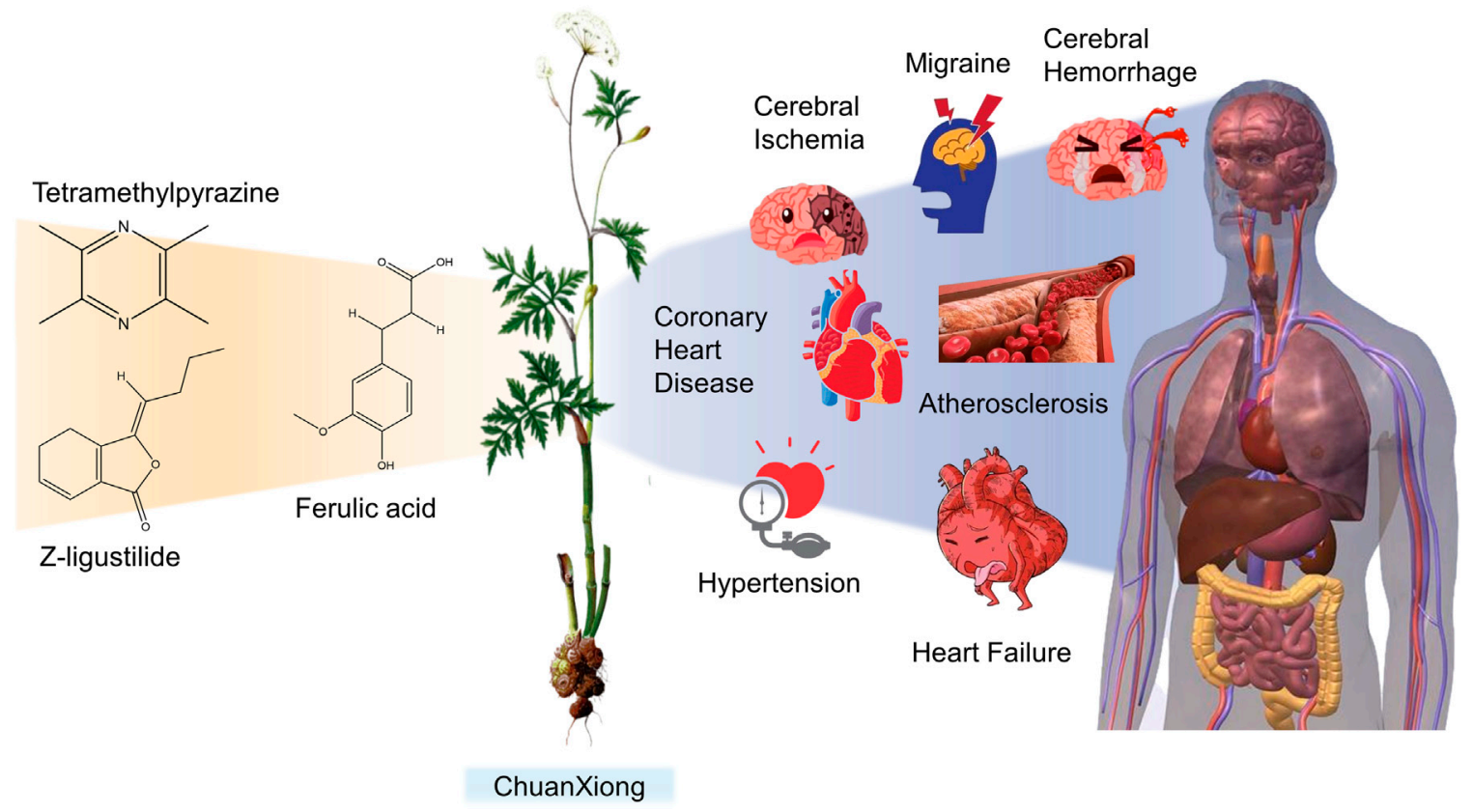

FIGURE 1 | Basic information of Ligusticum chuanxiong Hort. (CX contains tetramethylpyrazine, Z-ligustilide, ferulic acid, and other components, which are widely used in CVDs, including hypertension, CHD, AS, heart failure, cerebral ischemia, and cerebral hemorrhage).

of CX, such as volatile oils, organic acids, phenolic acids, phthalides, alkaloids, polysaccharides, ceramides, cerebrosides (Ran et al., 2011; Hung and Wu, 2016), and terpenoids (Chen et al., 2018). More than 80 compounds of which belong to various different structural types that have been identified (Li et al., 2012), including tetramethylpyrazine (TMP), ligustilide, senkyunolide A, ferulic acid, and other substances. At present, researches on active components of CX mainly focus on phthalides, alkaloids, and phenolic acids, while researches on other components are relatively few (Li, 2017). TMP and ferulic acid are the more functional and structural representatives of CX (Guo et al., 2016), among which TMP is the most active compound (Zhi-Gang et al., 2015). Based on the study of compounds isolated from CX, 42 compounds that have been proved to have CVD's protective effects are summarized in this article (Table 1).

\subsection{Volatile Oil}

CX contains $1 \%$ volatile oil, of which phthalides are the most important compounds, widely existing in Angelica sinensis (Oliv.) Diels (Danggui, DG), CX, and other umbelliferous plants, with low polarity and unstable heating characteristics (Fang et al., 2020). The phthalides in CX include more than 30 kinds of phthalides such as Z-ligustilide, E-ligustilide, senkyunolide A, and butylphthalide (Li et al., 2012). Modern pharmacological studies have found that phthalides have a variety of pharmacological activities, and the potential mechanism of cardio-cerebrovascular protection is related to the antithrombotic and antiplatelet effects, neuroprotective effects, improving blood fluidity, and inhibition of the abnormal proliferation of vascular smooth muscle cells (VSMCs) (León et al., 2017). Ligustilide is the most important phthalide in CX, which can play a neuroprotective role in cerebral ischemic diseases through its antioxidant and anti-apoptosis (Long et al., 2020). Butylphthalide was listed as one of the drugs that can be used in the treatment of ischemic stroke in 2005 by the food and Drug Administration of China (Zou et al., 2018).

\subsection{Alkaloids}

Up to now, 20 kinds of alkaloids have been found from CX, among which TMP is the most studied alkaloid, in addition to adenine, Senkyunolide A and other components ( $\mathrm{Pu}$ et al., 2020a). TMP widely exists in Ligusticum species (Donkor et al., 2016). It was first extracted from CX in 1937 (Cai et al., 2014), and also used as one of the quality evaluation materials of CX (Pu et al., 2020a). It has been used effectively since the 1970s to treat ischemic heart disease, cerebrovascular and thrombotic vascular diseases (Hintz and Ren, 2003). Modern pharmacological studies have found that alkaloids have a variety of pharmacological activities. The potential mechanisms of cardio-cerebrovascular protection are related to antiplatelet aggregation, antithrombotic, antioxidant, antiinflammatory, inhibition of abnormal proliferation of VSMCs, and neuroprotection (Pu et al., 2020b).

\subsection{Phenolic Acids}

The total phenolic acids of CX is the basis of the pharmacodynamic substance in CX, containing not less than 18 kinds of phenolic acids ( $\mathrm{Li}$ et al., 2012), which are given priority to with ferulic and chlorogenic acids (Pu et al., 2018). Ferulic acid is an effective component in CX and DG (Luo et al., 2019a), and its content is high in CX. It is often used as the quality control index of CX (Zhang et al., 2018b). According to the 
TABLE 1 | The pharmacodynamic material basis of Ligusticum chuanxiong Hort. in the treatment of CVDs.

\begin{tabular}{|c|c|c|c|c|c|c|c|}
\hline Number & Component & Classification & Structural form & CAS & $\begin{array}{c}\text { Molecular } \\
\text { formula }\end{array}$ & $\begin{array}{c}\text { Molecular } \\
\text { weight }\end{array}$ & Reference \\
\hline 1 & Z-Ligustilide & Volatile oil & & $4431-01-0$ & $\mathrm{C}_{12} \mathrm{H}_{14} \mathrm{O}_{2}$ & $190.24 \mathrm{~g} / \mathrm{mol}$ & $\begin{array}{l}\text { Yi et al. (2006), } \\
\text { Zhou et al. (2019b) }\end{array}$ \\
\hline 2 & E-Ligustilide & Volatile oil & & 81944-08-3 & $\mathrm{C}_{12} \mathrm{H}_{14} \mathrm{O}_{2}$ & $190.24 \mathrm{~g} / \mathrm{mol}$ & $\begin{array}{l}\text { Yi et al. (2006), } \\
\text { Zhou et al. (2019b) }\end{array}$ \\
\hline 4 & Senkyunolide H & Volatile oil & & $94596-27-7$ & $\mathrm{C}_{12} \mathrm{H}_{16} \mathrm{O}_{4}$ & $224.25 \mathrm{~g} / \mathrm{mol}$ & $\begin{array}{l}\text { Yi et al. (2006), } \\
\text { Han et al. (2018) }\end{array}$ \\
\hline 7 & Butylphthalide & Volatile oil & & $6066-49-5$ & $\mathrm{C}_{12} \mathrm{H}_{14} \mathrm{O}_{2}$ & $190.24 \mathrm{~g} / \mathrm{mol}$ & $\begin{array}{l}\text { Yi et al. (2006), } \\
\text { He et al. (2021) }\end{array}$ \\
\hline 8 & $\beta$-Elemene & Volatile oil & & 515-13-9 & $\mathrm{C}_{15} \mathrm{H}_{24}$ & $204.35 \mathrm{~g} / \mathrm{mol}$ & $\begin{array}{l}\text { Liu et al. (2017b), } \\
\text { Zhang et al. (2019) }\end{array}$ \\
\hline 9 & Squalene & Volatile oil & & $111-02-4$ & $\mathrm{C}_{30} \mathrm{H}_{50}$ & $410.7 \mathrm{~g} / \mathrm{mol}$ & $\begin{array}{l}\text { Zhang et al. (2019), } \\
\text { 'Izzah Ibrahim et al. } \\
\text { (2020) } \\
\text { d on following page) }\end{array}$ \\
\hline
\end{tabular}


TABLE 1 | (Continued) The pharmacodynamic material basis of Ligusticum chuanxiong Hort. in the treatment of CVDs.

\begin{tabular}{|c|c|c|c|c|c|c|c|}
\hline Number & Component & Classification & Structural form & CAS & $\begin{array}{l}\text { Molecular } \\
\text { formula }\end{array}$ & $\begin{array}{l}\text { Molecular } \\
\text { weight }\end{array}$ & Reference \\
\hline 10 & $a$-Pinene & Volatile oil & & $80-56-8$ & $\mathrm{C}_{10} \mathrm{H}_{16}$ & $136.23 \mathrm{~g} / \mathrm{mol}$ & $\begin{array}{l}\text { Zhang et al. (2019); } \\
\text { Khoshnazar et al. } \\
\text { (2020) }\end{array}$ \\
\hline 11 & $\beta$-Myrcene & Volatile oil & & $123-35-3$ & $\mathrm{C}_{10} \mathrm{H}_{16}$ & $136.23 \mathrm{~g} / \mathrm{mol}$ & $\begin{array}{l}\text { Burcu et al. (2016), } \\
\text { Zhang et al. (2019) }\end{array}$ \\
\hline 12 & Terpinen-4-ol & Volatile oil & & $562-74-3$ & $\mathrm{C}_{10} \mathrm{H}_{18} \mathrm{O}$ & $154.25 \mathrm{~g} / \mathrm{mol}$ & $\begin{array}{l}\text { Maia-Joca et al. } \\
\text { (2014), Zhang et al. } \\
\text { (2019) }\end{array}$ \\
\hline 13 & Spathulenol & Volatile oil & & $6750-60-3$ & $\mathrm{C}_{15} \mathrm{H}_{24} \mathrm{O}$ & $220.35 \mathrm{~g} / \mathrm{mol}$ & $\begin{array}{l}\text { Suručić et al. (2017), } \\
\text { Zhang et al. (2019) }\end{array}$ \\
\hline 14 & Levistilide A & Volatile oil & & $88182-33-6$ & $\mathrm{C}_{24} \mathrm{H}_{28} \mathrm{O}_{4}$ & $380.5 \mathrm{~g} / \mathrm{mol}$ & Tong, (2021) \\
\hline 16 & Terpinolene & Volatile oil & & $586-62-9$ & $\mathrm{C}_{10} \mathrm{H}_{16}$ & $136.23 \mathrm{~g} / \mathrm{mol}$ & Labdelli et al. (2019) \\
\hline 17 & Osthole & Volatile oil & & $484-12-8$ & $\mathrm{C}_{15} \mathrm{H}_{16} \mathrm{O}_{3}$ & $224.28 \mathrm{~g} / \mathrm{mol}$ & $\begin{array}{l}\text { Shengzhong et al. } \\
\text { (2019) }\end{array}$ \\
\hline 18 & Neocnidilide & Volatile oil & & $4567-33-3$ & $\mathrm{C}_{12} \mathrm{H}_{18} \mathrm{O}_{2}$ & $194.27 \mathrm{~g} / \mathrm{mol}$ & Tang et al. (2021) \\
\hline
\end{tabular}

(Continued on following page) 
TABLE 1 | (Continued) The pharmacodynamic material basis of Ligusticum chuanxiong Hort. in the treatment of CVDs.

\begin{tabular}{|c|c|c|c|c|c|c|c|}
\hline Number & Component & Classification & Structural form & CAS & $\begin{array}{l}\text { Molecular } \\
\text { formula }\end{array}$ & $\begin{array}{c}\text { Molecular } \\
\text { weight }\end{array}$ & Reference \\
\hline 19 & $\begin{array}{l}\text { Z-6,7- } \\
\text { Epoxyligustilide }\end{array}$ & Volatile oil & & $\begin{array}{c}106533- \\
40-8\end{array}$ & $\mathrm{C}_{12} \mathrm{H}_{14} \mathrm{O}_{3}$ & $206.24 \mathrm{~g} / \mathrm{mol}$ & Liu et al. (2004) \\
\hline 20 & Marmesin & Volatile oil & & $13848-08-6$ & $\mathrm{C}_{14} \mathrm{H}_{28} \mathrm{O}_{2}$ & $246.26 \mathrm{~g} / \mathrm{mol}$ & Kim et al. (2015) \\
\hline 21 & $\beta$-Sitosterol & Volatile oil & & $83-46-5$ & $\mathrm{C}_{29} \mathrm{H}_{50} \mathrm{O}$ & $414.7 \mathrm{~g} / \mathrm{mol}$ & Koc et al. (2020) \\
\hline 22 & Wallichilide & Volatile oil & & - & $\mathrm{C}_{25} \mathrm{H}_{32} \mathrm{O}_{5}$ & $412.5 \mathrm{~g} / \mathrm{mol}$ & Kailin et al. (2021) \\
\hline 23 & 3-Carene & Volatile oil & & - & - & - & $\begin{array}{l}\text { Sedigheh et al. } \\
\text { (2013) }\end{array}$ \\
\hline 24 & $\beta$-Eudesmol & Volatile oil & & - & - & - & Acharya et al. (2021) \\
\hline 25 & Tetramethylpyrazine & Alkaloid & & $1124-11-4$ & $\mathrm{C}_{8} \mathrm{H}_{12} \mathrm{~N}_{2}$ & $136.19 \mathrm{~g} / \mathrm{mol}$ & $\begin{array}{l}\text { Li and Chen (2004), } \\
\text { Mi et al. (2020) }\end{array}$ \\
\hline 26 & Adenosine & Alkaloid & & $58-61-7$ & $\mathrm{C}_{10} \mathrm{H}_{13} \mathrm{~N}_{5} \mathrm{O}_{4}$ & $267.24 \mathrm{~g} / \mathrm{mol}$ & Guieu et al. (2020) \\
\hline 27 & Inosine & Alkaloid & & 58-63-9 & $\mathrm{C}_{10} \mathrm{H}_{12} \mathrm{~N}_{4} \mathrm{O}_{5}$ & $268.63 \mathrm{~g} / \mathrm{mol}$ & Lima et al. (2020) \\
\hline
\end{tabular}


TABLE 1 | (Continued) The pharmacodynamic material basis of Ligusticum chuanxiong Hort. in the treatment of CVDs.

\begin{tabular}{|c|c|c|c|c|c|c|c|}
\hline Number & Component & Classification & Structural form & CAS & $\begin{array}{l}\text { Molecular } \\
\text { formula }\end{array}$ & $\begin{array}{l}\text { Molecular } \\
\text { weight }\end{array}$ & Reference \\
\hline 28 & Uridine & Alkaloid & & $58-96-8$ & $\mathrm{C}_{9} \mathrm{H}_{12} \mathrm{~N}_{2} \mathrm{O}_{6}$ & $244.2 \mathrm{~g} / \mathrm{mol}$ & Krylova et al. (2021) \\
\hline 29 & Choline & Alkaloid & & $62-49-7$ & $\mathrm{C}_{5} \mathrm{H}_{14} \mathrm{NO}^{+}$ & $104.17 \mathrm{~g} / \mathrm{mol}$ & Longzhu et al. (2017) \\
\hline 30 & Ferulic acid & Phenolic acid & & $1135-24-6$ & $\mathrm{C}_{10} \mathrm{H}_{10} \mathrm{O}_{4}$ & $194.18 \mathrm{~g} / \mathrm{mol}$ & $\begin{array}{l}\text { Yi et al. (2006), Zhou } \\
\text { et al. (2019b) }\end{array}$ \\
\hline 31 & Neochlorogenic acid & Phenolic acid & & $906-33-2$ & $\mathrm{C}_{16} \mathrm{H}_{18} \mathrm{O}_{9}$ & $354.31 \mathrm{~g} / \mathrm{mol}$ & $\begin{array}{l}\text { Liu et al. (2017a), } \\
\text { Zhang et al. (2017) }\end{array}$ \\
\hline 32 & Caffeic acid & Phenolic acid & & $\begin{array}{l}331-39-5 / \\
501-16-6\end{array}$ & $\mathrm{C}_{9} \mathrm{H}_{8} \mathrm{O}_{4}$ & $180.16 \mathrm{~g} / \mathrm{mol}$ & Gang (2018) \\
\hline 34 & Vanillic acid & Phenolic acid & & $121-34-6$ & $\mathrm{C}_{8} \mathrm{H}_{8} \mathrm{O}_{4}$ & $168.15 \mathrm{~g} / \mathrm{mol}$ & Xiuya et al. (2020) \\
\hline 35 & Palmitic acid & Phenolic acid & & $57-10-3$ & $\mathrm{C}_{16} \mathrm{H}_{32} \mathrm{O}_{2}$ & $256.42 \mathrm{~g} / \mathrm{mol}$ & Haibo et al. (2021) \\
\hline 36 & Vanillin & Phenolic acid & & $121-33-5$ & $\mathrm{C}_{8} \mathrm{H}_{8} \mathrm{O}_{3}$ & $152.15 \mathrm{~g} / \mathrm{mol}$ & $\begin{array}{l}\text { Sirangelo et al. } \\
\text { (2020) }\end{array}$ \\
\hline 37 & Tetradecanoic acid & Phenolic acid & & $544-63-8$ & $\mathrm{C}_{14} \mathrm{H}_{28} \mathrm{O}_{2}$ & $228.37 \mathrm{~g} / \mathrm{mol}$ & Oliviero et al. (2020) \\
\hline
\end{tabular}


TABLE 1 | (Continued) The pharmacodynamic material basis of Ligusticum chuanxiong Hort. in the treatment of CVDs.

\begin{tabular}{|c|c|c|c|c|c|c|c|}
\hline Number & Component & Classification & Structural form & CAS & $\begin{array}{l}\text { Molecular } \\
\text { formula }\end{array}$ & $\begin{array}{c}\text { Molecular } \\
\text { weight }\end{array}$ & Reference \\
\hline 38 & Gallic acid & Phenolic acid & & $149-91-7$ & $\mathrm{C}_{7} \mathrm{H}_{6} \mathrm{O}_{5}$ & $170.12 \mathrm{~g} / \mathrm{mol}$ & Jin et al. (2018) \\
\hline 39 & Protocatechuic acid & Phenolic acid & & $99-50-3$ & $\mathrm{C}_{7} \mathrm{H}_{6} \mathrm{O}_{4}$ & $154.12 \mathrm{~g} / \mathrm{mol}$ & Liyan et al. (2021) \\
\hline 40 & Chlorogenic & Phenolic acid & & $327-97-9$ & $\mathrm{C}_{16} \mathrm{H}_{18} \mathrm{O}_{9}$ & $354.31 \mathrm{~g} / \mathrm{mol}$ & $\begin{array}{l}\text { Bhandarkar et al. } \\
\text { (2018) }\end{array}$ \\
\hline 41 & Chrysophanic acid & Phenolic acid & & $481-74-3$ & $\mathrm{C}_{15} \mathrm{H}_{10} \mathrm{O}_{4}$ & $254.24 \mathrm{~g} / \mathrm{mol}$ & Lian et al. (2017) \\
\hline 42 & Daucosterol & Others & & $474-58-8$ & $\mathrm{C}_{35} \mathrm{H}_{60} \mathrm{O}_{6}$ & $576.8 \mathrm{~g} / \mathrm{mol}$ & Wang et al. (2018) \\
\hline
\end{tabular}

Chinese Pharmacopoeia 2020, the content of ferulic acid in dried CX should not be less than $0.01 \%$. Modern pharmacological studies have found that CX phenolic acid has a variety of pharmacological activities. The potential mechanism of cardiocerebrovascular protection is related to neuroprotective effect and regulation of inflammatory metabolism (He et al., 2018; Bao et al., 2019).

\subsection{Polysaccharides}

Polysaccharides widely exist in higher animals, plants, algae, and fungi. As a kind of biological macromolecule, its biological activity is related to its complex structure (Zhang, 2011). Research on the chemical composition of CX has been carried out since the 1950s, while research on CX polysaccharide only started in 2008. CX polysaccharide is composed of glucose, galactose, arabinose, xylose, rhamnose, and mannose ( $\mathrm{Li}$ et al., 2017a). Modern pharmacological studies have found that CX polysaccharide has a variety of pharmacological activities. The potential mechanism of cardio-cerebrovascular protection is related to antioxidant and anti-inflammatory (Zhao et al., 2017).

\subsection{Other Categories}

Glycosides, ceramides, cerebrosides, terpenoids, steroids, flavonoids, and other components were also found in CX (Li, 2017). Wang et al.
(2018) found that daucosterol was one of the effective components in the treatment of cerebrovascular diseases when analyzing the active components of Erigeron breviscapus (Vant.) Hand.-Mazz.

\section{PHARMACOLOGICAL ACTION OF LIGUSTICUM CHUANXIONG HORT.}

Better understanding of the CX effective components has revealed a complex regulatory mechanism, and these interactions are influenced by each other and form a wide, complex, and multi-directional regulatory network. These effects include anti-inflammatory, antioxidant, maintenance of endothelial cell stability, etc., which are usually associated with the course of CVDs. A systematic understanding of the mechanism of $\mathrm{CX}$ is conducive to guiding its clinical application. Here, we sorted out the complex network mechanism of CX in the CVDs, which is a powerful means to enrich our understanding of the "multi-link and multi-target" therapeutic mechanism of CX (Figure 2).

\subsection{Inhibition of Inflammatory Mediators}

Inflammation is a common pathophysiological sign of complex diseases, including AS and myocardial damage, that has recently 


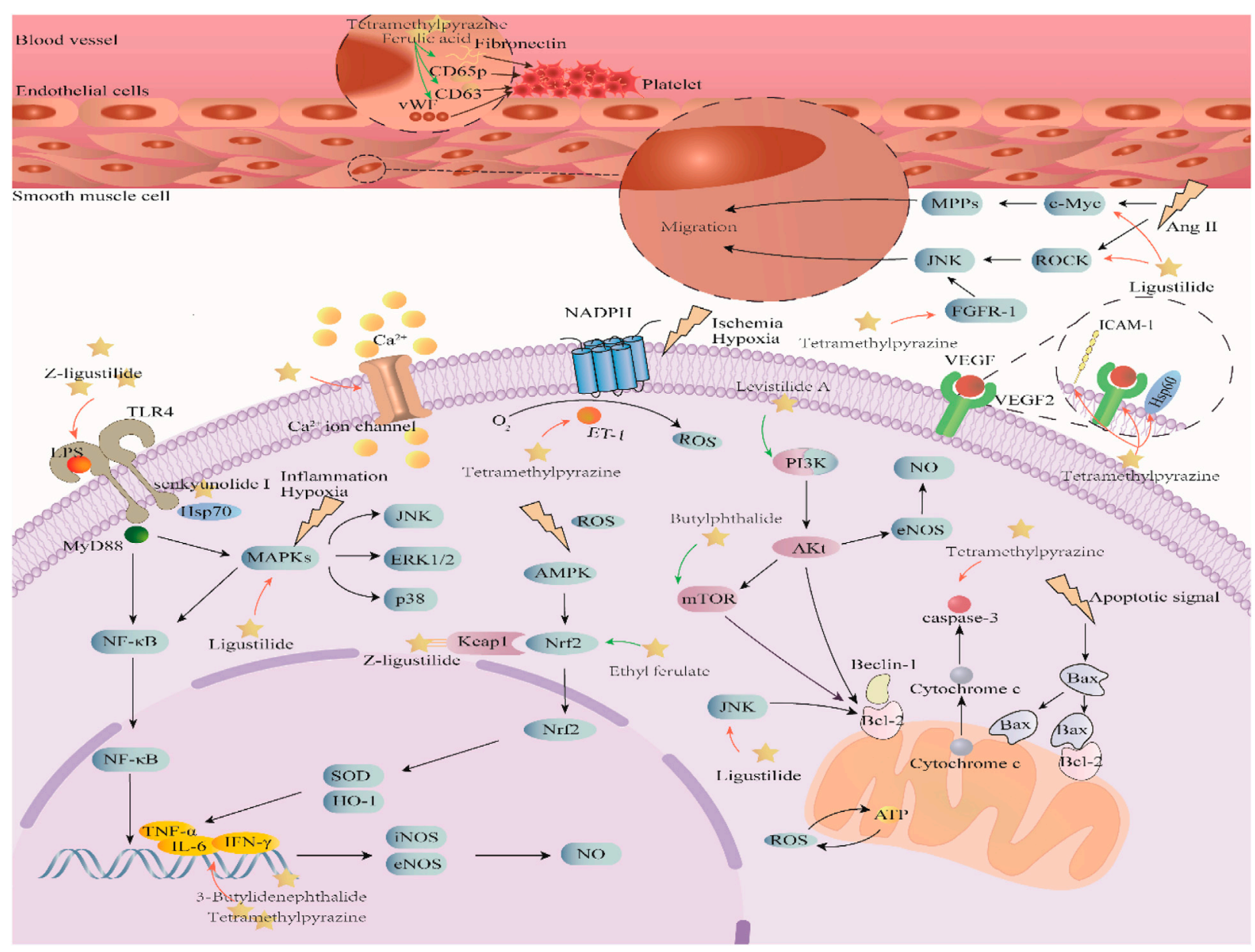

FIGURE 2 | Mechanism and pathway of Ligusticum chuanxiong Hort. in the treatment of CVDs.

emerged as an important contributor for CVDs development. In addition, it further exacerbates its harmful cardiovascular effects by interacting with the cardiovascular risk factors, thus creating a vicious cycle (Luca et al., 2020). The continuous increase of inflammatory mediators and the decrease of circulating antiinflammatory cytokines may aggravate the remodeling of vascular extracellular matrix (ECM) and arteriosclerosis, thus expanding pulse pressure, promoting systolic blood pressure, and aggravating cardiovascular conditions (Hirofumi et al., 2017).

In CX, phthalides, such as senkyunolide A, senkyunolide I, and Z-ligustilide, ethyl ferulate, and other components can inhibit the expression of inflammatory factors and achieve antiinflammatory effect. This effect may be realized through the Hsp70/TLR4/NF-kB, MAPK, and AMPK/Nrf2 pathways. The microglia are resident macrophages in the brain, which are activated during ischemia and produce various inflammatory mediators, including tumor necrosis factor- $\alpha$ (TNF- $\alpha$ ), NO, interleukin-6 (IL-6), and interleukin-1 (IL-1). Among them, TNF- $\alpha$ induces post-stroke injury in a variety of ways (Or et al., 2011). Senkyunolide A and Z-ligustilide inhibit the expression of iNOS and TNF- $\alpha$-mRNA in the microglia and protect neuro-2A cells from activated microglia-induced cytotoxicity (Or et al., 2011). The contents of NO, TNF- $\alpha$, and interleukin-1 $\beta$ (IL-1 $\beta$ ) in the lipopolysaccharide (LPS)-induced rat brain microglia were decreased and the activation of the microglia was inhibited by butenylphthalide (Nam et al., 2013). Toll-like receptors (TLRs) are highly conserved members of the interleukin-1 receptor superfamilies, which can result in the activation of innate immune responses. Most TLRs are activated by the protein products produced by myeloid differentiation primary gene 88 (MyD88). Activation of the TLRs makes the nuclear factor kappa-B (NF-kB) activated, moves it to the nucleus, and initiates the transcription of immune-related genes, including interferon- $\gamma$ (IFN- $\gamma$ ), IL-6, TNF- $\alpha$, and so on (Mayra et al., 2015). The extracellular heat shock protein 70 (Hsp70) is an endogenous ligand of TLR4 and can inhibit TLR4 through negative regulation to play a protective role. Senkyunolide I inhibits oxygen glucose deprivation/ reoxygenation-induced TLR4 elevation, and decreases MyD88 expression and NF- $\mathrm{KB}$ nuclear translocation. At the same time, the Hsp70 gene is silenced by siRNA before senkyunolide I treatment. It has been found that downregulation of Hsp70 enhanced the expression of TLR4 and weakened the inhibitory effect of senkyunolide I on NF- $\mathrm{kB}$ (Hu et al., 2016b). In addition, 
TLRs can also activate MAPK, and p38 mitogen-activated protein kinase (p38MAPK), c-Jun terminal kinases (JNKs), and ERK1/2 that have been identified as three major subgroups of MAPKs. p38 and JNK, as two major pathways of MAPK signal transduction, play an important role in inflammatory diseases (Zhou et al., 2019b). Hypoxia and inflammatory factors can activate the p38MAPK and JNK signaling pathways, but the downregulation of p38 MAPK and JNKs can reduce brain injury and neurologic deficit of focal cerebral ischemia and contribute to nerve protection (Gu et al., 2018). Ligustilide can reverse nitroprusside-induced activation of JNK and P38MAPK (Zhou et al., 2019b). In addition, adenosine monophosphate-activated protein kinase (AMPK) can reduce the inflammatory response, and ethyl ferulate can enhance the phosphorylation of AMPK, increase the expression of downstream Nrf2 gene, and promote its nuclear translocation. AMPK inhibitor could reverse the increase of Nrf2 expression caused by ethyl ferulate, and ethyl ferulate did not show the effect of increasing Nrf2 expression in Nrf2 knockout mice (Ya-Xian et al., 2021). The above data can well explain the antiinflammatory effect of ethyl ferulate, which can be realized through activation of the AMPK/Nrf2 pathway.

\subsection{Antioxidant}

Oxidative stress (OS) greatly leads to endothelial dysfunction and increases the risk of cardiovascular and cerebrovascular events (Heitzer et al., 2001). Excessive reactive oxygen species (ROS) are its direct primers, including the forms of hydroxyl radical $(\mathrm{OH})$, superoxide anion $\left(\mathrm{O}^{2-}\right)$ and hydrogen peroxide $\left(\mathrm{H}_{2} \mathrm{O}_{2}\right)$, which have become key mediators in the pathogenesis of vascular diseases such as stroke (Davis et al., 2019). Absolute and relative ischemia and hypoxia cause the decrease of oxygen supply and energy supply, which is the primary factor causing OS (Yang and Shanshan, 2015). Under the induction of cerebral ischemia, the energy consumption in the brain can promote the activity of OS. The highly activated nicotinamide adenine dinucleotide photosphate (NADPH) oxidase will produce excessive ROS to aggravate the damage (Ni et al., 2014). In addition, a large number of ROS can cause changes in mitochondrial membrane potential, enhancing its permeability and damaging mitochondria. The loss of ATP synthesis further exacerbates ROS production, creating a vicious cycle (Yang and Shanshan, 2015). Excessive ROS can cause fatal influence to the cells and organs, transforming the redox equilibrium state into a pro-oxidation state. ROS can block blood circulation, destroy epithelial cells and inhibit vasodilation by affecting blood vessels (Lin et al., 2019).

A variety of components in CX can exert antioxidant effects, which may be realized through the Nrf2 pathway and inhibition of NADPH enzyme. Superoxide dismutase (SOD) is an important enzyme for ROS removal in the body; the total antioxidant capacity (T-AOC) is the overall level of antioxidants in the body, which can reflect the antioxidant capacity of the body; malondialdehyde (MDA) is the final product of ROS lipid peroxidation, which can reflect the degree of lipid peroxidation. CX extract can reverse the decrease of SOD and $\mathrm{T}$-AOC and the increase of MDA in the myocardial ischemia model, showing its antioxidant ability (Wang et al., 2017b). When OS occurs, the synthesis of redox sensitive transcription factor NF-E2-related factor 2 (Nrf2) is increased and Nrf2 is activated, increasing Nrf2 transfer from the cytoplasm to the nucleus. The upregulation of heme oxygenase-1 (HO-1) and SOD expression results in NF- $\kappa$ B failure and alleviates OS injury (Li et al., 2017b). Studies have shown that, as an antioxidant, TMP can exert its antioxidant effect by directly scavenging ROS or inhibiting the activity of the main source of ROS, namely NADPH oxidase (Jiang et al., 2011). Angiotensin II (AngII) can stimulate NADPH oxidase to produce ROS in VSMCs, which can be induced by endothelin-1 (ET-1). TMP can significantly inhibit the expression of ET-1 mRNA induced by AngII, reduce the activity of NADPH enzyme, and reduce the expression of ROS (Wong et al., 2007).

\subsection{Protection of Endothelial Cells}

Vascular events are caused by many factors of complex events. Endothelial cells play an important role in the regulation of vascular homeostasis and are closely related to the regulation of vascular tone, platelet activity, leukocyte adhesion, and thrombosis (Heitzer et al., 2001). Endothelial dysfunction is almost the common denominator of most vascular events (Ni et al., 2014), which is the earliest indicator of the development of cardiovascular disease. Vascular endothelium is a selective blood and tissue barrier that promotes angiogenesis and is necessary for tissues to adequately meet their metabolic and functional needs over the long term. Vascular endothelial cells (VECs) can promote angiogenesis and further aggravate inflammationrelated injuries, causing plaque dilation, internal bleeding, and rupture, and promoting atherosclerotic lesions (Zhang et al., 2014; Wang et al., 2015). Therefore, inhibition of VECs growth can help treat AS.

TMP, levistilide A, and other components of CX play an important role in maintaining normal physiological functions of VECs, which may be achieved by inhibiting proliferation of endothelial cells, inhibiting the VEGF/VEGFR2 pathway, activating the PI3K-Akt-ENOS pathway, reducing ROS and icAM-1 and HSP60 expressions. Vascular endothelial growth factor (VEGF) is a key pro-angiogenic factor that promotes angiogenesis by activating VEGF2 receptors on the endothelial cells. Yuan et al. (2018) found that in the model of human umbilical vein endothelial cells (HUVECs) when induced by low concentrations of oxidized low-density lipoprotein (LDL), the number of vascular branch points increased and angiogenesis-related proteins VEGF and VEGF2 were upregulated. After TMP treatment, VEGF2 was downregulated, but VEGF was not affected. These data suggest that TMP can play a therapeutic role in reducing angiogenesis by inhibiting the VEGF/VEGFR2 pathway and inhibiting endothelial cell generation. $\mathrm{NO}$ is the key to maintaining endothelial function, and it can protect VECs by vasodilating in the physiological state. The activation of the PI3K-Akt pathway can affect the level of eNOS and thus increase the content of NO. Levistilide A can improve the continuity and integrity of damaged VECs and enhance their vitality. In addition to protecting VECs, the expression levels of $\mathrm{PI} 3 \mathrm{~K}, \mathrm{AKT}$, and eNOs proteins were increased (Tong, 2021). In addition, excessive ROS produced by 
VEC stress can also lead to endothelial dysfunction. $\mathrm{O}^{2-}$ is an ROS associated with the cytotoxicity of VECs, and $\mathrm{H}_{2} \mathrm{O}_{2}$ can produce $\mathrm{O}^{2-}$ by activating NADPH oxidase. Ni et al. (2014) found that TMP could improve Ach-induced relaxation of VECs and reverse $\mathrm{O}^{2-}$ induced by $\mathrm{H}_{2} \mathrm{O}_{2}$, which is consistent with the inhibition effect of NADPH oxidase. Under normal physiological functions, the expression levels of intracellular adhesion molecular-1 (ICAM-1) and heat shock protein 60 (HSP60) in VECs are low. However, when VECs are stimulated by inflammatory factors such as TNF- $\alpha$, the expressions of ICAM-1 and HSP60 are upregulated, which induces the expression of cell adhesion molecules and produces autoantibodies and autoimmune responses, which are one of the pathogenesis of AS. Wu et al. (2012) detected the levels of ICAM-1 and HSP60 in HUVECs under the influence of TNF- $\alpha$. It was found that the levels of ICAM-1 and HSP60 of HUVECs stimulated by TNF- $\alpha$ were significantly reduced before and after TMP administration, thus achieving protective effect against VECs disorders and reducing leukocyte adhesion.

\subsection{Influence on Autophagy and Apoptosis}

Apoptosis is a gene-controlled leukocyte death process-also known as programmed cell death under physiological conditions, is one of the mechanisms to maintain the stability of the internal environment, and is also an important mechanism of cerebral ischemia reperfusion and other diseases. Autophagy, also known as type ii programmed cell death, is often used as a protective mechanism. Under normal physiological conditions, it can remove damaged organelles, protein aggregates, and invading pathogens and maintain cell homeostasis. Under pathological conditions, the over-activation or inhibition of autophagy is often accompanied by a variety of diseases, including AS, myocardial ischemia-reperfusion injury, heart failure, and other cardiovascular diseases (Wang et al., 2017a; Demin et al., 2018). Autophagy and apoptosis are a double-edged sword and are balanced by Beclin-1 and Bcl-2. Beclin-1 can promote autophagy under the regulation of a variety of proteins, but this pro-autophagy binding can be blocked by anti-apoptotic Bcl-2 protein. Activation of PI3K/Akt phosphatidylinositol 3-kinase/ serine/threonine kinase (PI3K/Akt) pathway can promote the interaction between Beclin-1 and $\mathrm{Bcl}-2$ protein, thereby inhibiting autophagy (Wang et al., 2017a). Phosphorylation of Beclin-1 and Bcl-2 alone can lead to the separation of the two proteins, for example, phosphorylation of Bcl-2 by JNK promotes autophagy. In addition, JNK and P38 are major pathways of MAPK signaling and play important roles in stimulating apoptotic signals and inflammation. It has been found that Bcl-2 family plays an important role in apoptosis caused by mitochondrial dysfunction. Bax can promote apoptosis, and Bcl-2 can resist apoptosis (Jun et al., 2015). When the mitochondrial membrane potential changes, cytochrome $\mathrm{c}$ will be released to the cytoplasm, which stimulates Caspase-3. Bcl-2 located on the outer membrane of the mitochondria can prevent the release of pro-apoptotic proteins such as cytochrome c. After receiving the apoptosis signal, the inactive monomer protein Bax, which is free in the cytoplasm, moves to the outer membrane of the mitochondria and forms a channel, damaging the integrity of the mitochondrial membrane and antagonizing bcl-2 to prevent it from exerting the anti-apoptotic effect.

The volatile oil components in $\mathrm{CX}$, including ligustilide, butylphthalide, senkyunolide A, H, and I, and TMP can play a therapeutic role in myocardial ischemia and cerebral ischemia-reperfusion injury by regulating autophagy and apoptosis. This role may be related to the PI3K/Akt/mTOR pathway, the MAPK pathway, and mitochondrial dependence. Cystine protease P32, also known as Caspase-3, is one of the most important pro-apoptotic factors of the Caspase family members and the common effector of multiple apoptotic pathways. Butylphthalide pretreatment can inhibit the expression of Caspase- 3 and increase the level of p-Akt, an Akt phosphorylation product, in the brain of rats with cerebral ischemia-reperfusion injury (Yan, 2013). It shows that butylphthalide may achieve the effect of anti-apoptosis by activating the PI3K/Akt pathway. The mammalian target of rapamycin (mTOR) is a negative regulator of autophagy. Ligustilide can upregulate the expression of p-pI3k, p-Akt, and $\mathrm{p}$-mTOR proteins in the brain of rats with cerebral ischemia-reperfusion and show the activation of the PI3K/ Akt/mTOR pathway. It also upregulated $\mathrm{Bcl}-2$ protein and downregulated the levels of pro-apoptotic protein Bax and Caspase-3 mRNA (Bo et al., 2021). The lactone components of CX (senkyunolide I: senkyunolide $\mathrm{H}$ : senkyunolide A: ligustilide $=1.00: 1.30: 6.90: 13.24)$ significantly increased the PI3K protein expression and Akt and mTOR protein phosphorylation levels, decreased Beclin-1 expression, and reduced the number of autophagic vesicles. The antiautophagy effect of lactone components of $\mathrm{CX}$ can be terminated by PI3K inhibitor LY94002, which shows that it can play a role by activating PI3K/Akt/mTOR pathway (Gang, 2018). In addition, TMP downregulated the level of Caspase- 3 and increased the ratio of $\mathrm{Bcl}-2 / \mathrm{Bax}$. This effect can be reversed by LY294002, a specific inhibitor of the PI3K/Akt signaling pathway (Su et al., 2019). Ligustilide can increase the expression of Bcl-2 and reduce the levels of Caspase-3, Bax, and iNOS. The effect of ligustilide can be reversed by JNK and p38MAPK agonist anisomycin (Zhou et al., 2019b). This shows that the inhibitory effect of ligustilide on apoptosis may be achieved by inhibiting JNK and p38 MAPK. Xuesong et al. (2019) found that the ratio of cytochrome $c$ and Cox IV in the mitochondria decreased and that in the cytoplasm increased in the model group. In addition, TUNEL and DAPI staining showed that the apoptosis in the model group reached $41 \%$, accompanied by the upregulation of Caspase- 3 and Bax/Bcl-2. TMP attenuated the change of mitochondrial membrane potential, inhibited the release of cytochrome $\mathrm{c}$ from the mitochondria to the cytoplasm, and decreased the expression of Caspase- 3 and Bax/Bcl-2.

\subsection{Inhibition of Smooth Muscle Cell Proliferation}

VSMCs, endothelial cells, and ECM are the same components of the vascular wall. In line with endothelial cells, VSMCs can control the diameter of the lumen by coordinating the contraction and relaxation of the vessels, thus maintaining 
blood pressure (Wei and $\mathrm{Wu}, 2020$ ). The proliferation, migration, and phenotypic transformation of VSMCs are one of the characteristics of vascular stenosis and the main pathological basis of vascular diseases. In addition, the phenotypic plasticity of VSMCs enables them to quickly adapt to environmental changes and plays an important role in CVDs (Park et al., 2019). NF- $\kappa B$ is a transcription factor commonly found in eukaryotes. When the body has an immune or stress response, NF- $\kappa \mathrm{B}$ is activated and then transferred to the nucleus where it can stimulate or inhibit the transcription of some genes (Wei, 2020).

Ligustilide and TMP in CX can inhibit the proliferation of VSMCs and maintain the normal function of blood vessels. This effect may be related to JNK phosphorylation, and the c-Myc/ MMP2 and ROCK/JNK pathway. Ligustilide can inhibit Ang II-induced VSMC migration and downregulate migration-related proteins c-Myc, MMP2, ROCK1, ROCK2, p-JNK, and JNK (Luo et al., 2019b). The increased expression of fibroblast growth factor receptor-1 (FGFR-1) can activate the phosphorylation of JNK and affect the migration of VSMCs. TMP can reduce the proliferation of VSMCs induced by PM2.5, accompanied by the decrease of FGFR-1 and JNK phosphorylation levels. This effect is consistent with the results of JNK inhibitor treatment, suggesting that TMP can inhibit the proliferation of VSMCs by reducing the phosphorylation level of JNK (Qiang et al., 2017). c-Myc gene regulates cell proliferation and migration, and its high expression can enhance cell motility. The matrix metalloproteinases (MMPs) can degrade most of the components of the extracellular matrix, destroy the basement membrane formed during migration, and damage its migration inhibition, so as to make cells migrate smoothly. Ang II increased the expression of protein and mRNA of c-Myc and MMPs. Transwell cell migration experiment also found that cell migration was enhanced. The treatment with ligustilide and c-Myc inhibitor showed the downregulation of the expression of c-Myc and MMPs, accompanied by the decrease of cell migration. It can be preliminarily determined that ligustilide can inhibit the migration of VSMCs through the c-Myc/MMP2 signaling pathway. Rho-GTP has an important relationship with cell migration. Rhoo-associated kinase (ROCK) is the related kinase of Rho and is necessary to mediate the actin structure and contraction response of VSMCs. Ligustilide can inhibit the expression of ROCK1 and ROCK2 induced by Ang II, activate Rho/ROCK pathway, reduce the expression of JNK, and form signal interaction, but the role of them is not clear. After treatment with ROCK-specific inhibitors, it was found that the decrease of ROCK1 and ROCK2 was accompanied by the decrease of JNK expression, suggesting that ligustilide can inhibit the migration of VSMCs by regulating the ROCK/JNK signaling pathway (Luo et al., 2019b).

\subsection{Adjust NO}

Nitric oxide synthase (NOS) is the only rate-limiting enzyme for NO production. It can be divided into endothelial NOS (eNOS), neuronal NOS (nNOS), and inducible NOS (iNOS). eNOS is mainly expressed in endothelial cells. Under normal conditions, eNOS produces a small amount of NO, which can dilate blood vessels and has a neuroprotective effect. Under pathological conditions, nNOS and iNOS produce a large amount of NO, play a neurotoxic role, and cause cerebrovascular dysfunction.

TMP and other components in CX can regulate NO, which may be achieved by inhibiting NOS. And IL-1 $\beta$, IL-2, IL-6, TNF- $\alpha$, IFN- $\beta$, and other proinflammatory cytokines can induce high expression of iNOS. TMP can inhibit the expression of eNOS and iNOS induced by LPS to downregulate the level of $\mathrm{NO}$ in the rat brain. The expression of IL-6, TNF- $\alpha$, and IL- $1 \beta$ was decreased (Sheng et al., 2020). It shows that CX can reduce the expression of NO by affecting proinflammatory cytokines and inhibiting NOS.

\subsection{Influence on Calcium Ions}

Intracellular $\mathrm{Ca}^{2+}$ homeostasis is necessary to maintain cell function. When cardiomyocytes are activated, changes in the cell membrane potential will open up L-type calcium current (ICA-L) and increase the amount of $\mathrm{Ca}^{2+}$ entering the cytoplasm from the outside of the cell. Large amounts of $\mathrm{Ca}^{2+}$ will bind to troponin, causing excitatory contraction of the myocardium and myocardial injury (Zhao et al., 2020). Therefore, calcium overload can be alleviated by inhibiting calcium channels and intracellular $\mathrm{Ca}^{2+}$ homeostasis can be maintained to achieve cardiac protection.

The regulating effect of TMP and other components in CX on calcium ions may be related to regulating calcium channels. TMP reduces $\mathrm{Ca}^{2+}$ increase in cells by selectively opening KATP or SKCa channels (Wong et al., 2003). Wu et al. (1989) found that at low doses, TMP predominantly prevents the mobilization of intracellular calcium, but at a higher dose, it inhibits the influx of extracellular calcium. Ren et al. (2012) found that TMP can dose-dependently reduce the ICA-L of rabbit cardiomyocytes, and this inhibition can be restored after elimination of the drug. At the same time, TMP can inhibit the transient and contraction of calcium in rabbit cardiomyocytes under physiological and pathological conditions.

\subsection{Anti-Platelet Aggregation}

Platelet activation and aggregation play a crucial role in AS. Platelet proteomics revealed that platelet gelsolin is a differential functional protein between patients with CHD and healthy people and is highly expressed in patients (Liu et al., 2013). In addition, platelet aggregation also plays an important role in thrombosis, which is related to AS, stroke, and various inflammatory reactions. Inhibition of platelet aggregation can effectively prevent and slow down the formation of thrombosis (Chen et al., 2017a).

TMP, ferulic acid, and other components in CX can inhibit platelet aggregation, which may be achieved by reducing platelet activation and the expression of adhesion molecules. TMP was used to treat patients with acute coronary syndrome (ACS) after percutaneous coronary intervention (PCI). It was found that the two platelet activation indexes of CD65p and CD63 decreased significantly before and after the treatment (Xu and $\mathrm{Li}, 2019$ ). TMP can reduce the expression of two adhesion molecules the von Willebrant Factor (vWF) and fibronectin in endothelial cells, inhibit platelet activation and aggregation, promote blood circulation and reduce platelet adhesion (Wang et al., 2016).

$\mathrm{Xu}$ and Li (2019) used TMP to treat ACS patients after PCI using CD65p, CD63 (two platelet activation markers), platelet adhesion 
TABLE 2 | Application of classical prescription containing Ligusticum chuanxiong Hort. in CVDs.

\begin{tabular}{|c|c|c|c|c|}
\hline Classics & Prescription & Therapeutic effect & Indication & Reference \\
\hline Golden Mirror of Medicine & Taohong Siwu decoction & $\begin{array}{l}\text { 1. Reduce the area of cerebral infarction and } \\
\text { reduce neurological damage; } \\
\text { 2. Promote blood circulation; } \\
\text { 3. Promote angiogenesis and reduce } \\
\text { apoptosis; } \\
\text { 4. Anticoagulation and lipid lowering; } \\
\text { 5. Inhibit apoptosis; } \\
\text { 6. Reduce myocardial fibrosis }\end{array}$ & $\begin{array}{l}\text { 1. Cerebral } \\
\text { ischemia-reperfusion injury; } \\
\text { 2. Acute blood stasis; } \\
\text { 3. Myocardial infarction; } \\
\text { 4. CHD; } \\
\text { 5. Middle cerebral artery } \\
\text { occlusion reperfusion; } \\
\text { 6. Myocardial infarction }\end{array}$ & $\begin{array}{l}\text { Li et al. (2015b), Tan } \\
\text { et al. (2021) }\end{array}$ \\
\hline $\begin{array}{l}\text { Correction on Errors in Medical } \\
\text { Classics }\end{array}$ & $\begin{array}{l}\text { Buyang Huanwu } \\
\text { decoction }\end{array}$ & $\begin{array}{l}\text { 1. Inhibit the proliferation of VSMCs; } \\
\text { 2. Improve hemorheological disorders and } \\
\text { energy metabolism; } \\
\text { 3. Neuroprotective effect; } \\
\text { 4. Reduce and inhibit excitatory amino acids; } \\
\text { 5. Improve synaptic plasticity and promote } \\
\text { nerve repair; } \\
\text { 6. Protect blood-brain barrier }\end{array}$ & $\begin{array}{l}\text { 1. } \mathrm{CHD} \text {; } \\
\text { 2. Ischemic stroke }\end{array}$ & $\begin{array}{l}\text { Chen et al. (2011), Pan } \\
\text { et al. (2017), Chen et al. } \\
\text { (2019c) }\end{array}$ \\
\hline $\begin{array}{l}\text { Correction on Errors in Medical } \\
\text { Classics }\end{array}$ & $\begin{array}{l}\text { Decoction for activating } \\
\text { blood circulation }\end{array}$ & $\begin{array}{l}\text { Dilate blood vessels, improve } \\
\text { microenvironment, and inhibit inflammatory } \\
\text { reaction }\end{array}$ & $\begin{array}{l}\text { 1. Cerebral infarction; } \\
\text { 2. Hypertension }\end{array}$ & Yang (2020b) \\
\hline Danxi's Mastery of Medicine & Yueju pill & $\begin{array}{l}\text { 1. Improve myocardial tissue antioxidant; } \\
\text { 2. Reduce inflammatory factors }\end{array}$ & $\begin{array}{l}\text { 1. Myocardial ischemia; } \\
\text { 2. Angina pectoris; } \\
\text { 3. Hypertension; } \\
\text { 4. Hyperlipidemia; } \\
\text { 5, CHD }\end{array}$ & $\begin{array}{l}\text { Gui et al. (2016), Hu } \\
\text { et al. (2017) }\end{array}$ \\
\hline $\begin{array}{l}\text { Essential Recipes for Emergent Use } \\
\text { Worth A Thousand Gold }\end{array}$ & Xiao Xu Ming decoction & $\begin{array}{l}\text { 1. Inhibit autophagy-related protein and } \\
\text { promote the recovery of neural function; } \\
\text { 2. Reduce the damage of blood-brain } \\
\text { barrier and cerebral ischemia; } \\
\text { 3. Improve cerebral artery blood supply and } \\
\text { hemodynamics, and promote the recovery } \\
\text { of neural function; } \\
\text { 4. Improve hemorheology, reduce blood } \\
\text { viscosity, and improve the increase of cell } \\
\text { aggregation; } \\
\text { 5. Dilate blood vessels, inhibit vascular motor } \\
\text { left, or sympathetic nervous system }\end{array}$ & $\begin{array}{l}\text { 1. Cerebral } \\
\text { ischemia-reperfusion; } \\
\text { 2. Acute cerebral infarction; } \\
\text { 3. Hyperlipidemia; } \\
\text { 4. Hypertension }\end{array}$ & $\begin{array}{l}\text { Lan et al. (2013), Cheng } \\
\text { et al. (2019), Wu and } \\
\text { Wang (2020) }\end{array}$ \\
\hline
\end{tabular}

\begin{tabular}{|c|c|c|c|c|}
\hline Clear Synopsis on Recipes & Dachuanxiong pill & $\begin{array}{l}\text { 1. Regulate hemorheology and } \\
\text { hemodynamics; } \\
\text { 2. Upregulate the level of VEGF }\end{array}$ & Cerebral ischemia & Zhang et al. (2006) \\
\hline $\begin{array}{l}\text { Correction on Errors in Medical } \\
\text { Classics }\end{array}$ & Xuefu Zhuyu decoction & $\begin{array}{l}\text { 1. Inhibit inflammation and inhibit apoptosis; } \\
\text { 2. Improve blood lipid and inhibit AS; } \\
\text { 3. Improve cerebral infarction, improve } \\
\text { neurological deficit; } \\
\text { 4. Reverse myocardial fibrosis; } \\
\text { 5. Reduce blood lipid and whole blood } \\
\text { viscosity, improve heart energy supply, and } \\
\text { regulate amino acid metabolism; } \\
\text { 6. Improve vascular endothelial function, } \\
\text { promote angiogenesis, and improve } \\
\text { hemorheology }\end{array}$ & $\begin{array}{l}\text { 1. Thromboembolic stroke; } \\
\text { 2. Hyperlipidemia; } \\
\text { 3. Acute ischemic stroke; } \\
\text { 4. Hypertension; } \\
\text { 5. CHD; } \\
\text { 6. AS }\end{array}$ & $\begin{array}{l}\text { Lee et al. (2011), Shen } \\
\text { et al. (2015) }\end{array}$ \\
\hline Clear Synopsis on Recipes & $\begin{array}{l}\text { Miraculous power of } \\
\text { Ledebouriella }\end{array}$ & $\begin{array}{l}\text { Promote and improve the level of lipid } \\
\text { metabolism, and improve and regulate lipid } \\
\text { metabolism and disorder }\end{array}$ & Hyperlipidemia & Xing (2002) \\
\hline $\begin{array}{l}\text { Prescriptions of the Bureau of Taiping } \\
\text { People's Welfare Pharmacy }\end{array}$ & $\begin{array}{l}\text { Decoction of } 10 \text { powerful } \\
\text { tonics }\end{array}$ & $\begin{array}{l}\text { Reduce the load of heart, improve the } \\
\text { congestion of organs }\end{array}$ & $\begin{array}{l}\text { 1. Heart failure after acute } \\
\text { myocardial infarction; } \\
\text { 2. CHF }\end{array}$ & $\begin{array}{l}\text { Pan and Liu, (2017), } \\
\text { Yang (2020a) }\end{array}$ \\
\hline General principles of Medicine & Chaihu Shugan powder & $\begin{array}{l}\text { 1. Reduce neurogenic inflammation; } \\
\text { 2. Improve heart function and inflammatory } \\
\text { reaction, and reduce adverse reactions }\end{array}$ & $\begin{array}{l}\text { 1. Stable angina pectoris of } \\
\text { CHD; } \\
\text { 2. Hypertension; } \\
\text { 3. Acute myocardial } \\
\text { infarction }\end{array}$ & $\begin{array}{l}\text { Hu et al. (2016a), Yang } \\
\text { et al. (2020b) }\end{array}$ \\
\hline
\end{tabular}

(Continued on following page) 
TABLE 2 | (Continued) Application of classical prescription containing Ligusticum chuanxiong Hort. in CVDs.

\begin{tabular}{|c|c|c|c|c|}
\hline Classics & Prescription & Therapeutic effect & Indication & Reference \\
\hline $\begin{array}{l}\text { Correction on Errors in Medical } \\
\text { Classics }\end{array}$ & $\begin{array}{l}\text { Infradiaphragmatic stasis- } \\
\text { expelling decoction }\end{array}$ & $\begin{array}{l}\text { 1. Improve hemorheology, reduce vascular } \\
\text { resistance, inhibit platelet aggregation and } \\
\text { release, increase plasmin activity, promote } \\
\text { fibrinolysis, improve microcirculation; } \\
\text { 2. Improve platelet aggregation, reduce } \\
\text { inflammatory reaction, and myocardial injury }\end{array}$ & $\begin{array}{l}\text { 1. Angina pectoris of } \mathrm{CHD} \text {; } \\
\text { 2. Myocardial infarction }\end{array}$ & $\begin{array}{l}\text { Liu et al. (2012), Liu } \\
\text { et al. (2018) }\end{array}$ \\
\hline Synopsis of Golden Chamber & $\begin{array}{l}\text { Danggui Shaoyao } \\
\text { powder }\end{array}$ & $\begin{array}{l}\text { 1. Improve the level of lipid peroxidation and } \\
\text { hemorheology; } \\
\text { 2. Improve the level of blood lipids; } \\
\text { 3. Reduce the concentration of } \\
\text { vasoconstrictors; } \\
\text { 4. Increase the blood supply to the brain }\end{array}$ & $\begin{array}{l}\text { 1. Hyperlipidemia; } \\
\text { 2. AS; } \\
\text { 3. Hypertension; } \\
\text { 4. Acute myocardial } \\
\text { infarction }\end{array}$ & Ren et al. (2017) \\
\hline SuWenBingJiQiYiBaoMingJi & Daqinjiao decoction & $\begin{array}{l}\text { 1. Improve blood pressure level and blood } \\
\text { pressure rhythm; } \\
\text { 2. Improve hemorheology and nerve } \\
\text { function; } \\
\text { 3. Improve the degree of nerve function } \\
\text { defect }\end{array}$ & $\begin{array}{l}\text { 1. Hypertension; } \\
\text { 2. Acute cerebral infarction; } \\
\text { 3. Acute ischemic stroke }\end{array}$ & $\begin{array}{l}\text { Song et al. (2018), Gao } \\
\text { et al. (2019) }\end{array}$ \\
\hline
\end{tabular}

\begin{tabular}{|c|c|c|c|}
\hline Category & Name & Indication & Reference \\
\hline \multirow[t]{9}{*}{ Capsule } & $\begin{array}{l}\text { Compound Chuanxiong } \\
\text { capsule }\end{array}$ & AS & Kang et al. (2015) \\
\hline & Xinnaokang capsule & Angina pectoris & Li et al. (2019) \\
\hline & Naoxintong capsule & $\begin{array}{l}\text { Heart failure, myocardial infarction, cerebral ischemia-reperfusion, cerebral } \\
\text { infarction }\end{array}$ & Wang et al. (2017c) \\
\hline & Niuhuang Jiangya capsule & Hypertension & Ma (2018a) \\
\hline & Zhengxin Tai capsule & Angina pectoris & Zhang and Qi (2015) \\
\hline & Xueshuan Xinmaining capsule & Acute cerebral infarction & Ma et al. (2019) \\
\hline & Xuemaitong capsule & Cerebral hemorrhage, acute myocardial infarction, AS, CHD, and angina pectoris & Wang et al. (2006), Ye et al. (2013) \\
\hline & Shuxin Tongmai capsule & $\mathrm{CHD}$ & Zhang and Gao (2019) \\
\hline & Guanxin Kang capsule & Heart failure, acute myocardial ischemia, CHD, and angina pectoris & Pan et al. (2007) \\
\hline \multirow[t]{4}{*}{ Granule } & Mailuotong granules & Cerebral infarction & Wang et al. (2020) \\
\hline & Zhengxintai granules & Angina pectoris & Li et al. (2005) \\
\hline & Yixin Tongmai granules & Angina pectoris & Wang and Shi (2015) \\
\hline & Guanxin Kang granules & Angina pectoris & Liu (2011) \\
\hline \multirow[t]{4}{*}{ Pill } & Guanxin pill & Angina pectoris & Feng (2006) \\
\hline & Angong Jiangya pill & Hypertension & Li and Wang (2019) \\
\hline & Suxiao Jiuxin pill & AS, acute myocardial ischemia, CHD, myocardial infarction & Li et al. (2011) \\
\hline & Niuhuang Jiangya pills & Hypertension & Yin (2018) \\
\hline \multirow[t]{4}{*}{ Tablet } & ShuXinNing tablets & Hypertension, high cholesterol, CHD, angina pectoris & Wang et al. (2018a) \\
\hline & Zhengxintai tablets & Angina pectoris & $\mathrm{Xu}(2007)$ \\
\hline & Xiaoshuan Tongluo tablets & Focal cerebral ischemia & Li et al. (2016) \\
\hline & Xueshuan Xinmaining tablets & $\mathrm{CHD}$ angina, $\mathrm{CHD}$ & Tan et al. (2018), Shan and Leng (2019) \\
\hline \multirow[t]{3}{*}{ Oral liquid } & Guanxin'an oral liquid & Myocardial ischemia & Wang et al. (2005) \\
\hline & Ruanmailing oral liquid & AS & Wu et al. (2013) \\
\hline & Tongtian oral liquid & Acute cerebral infarction & Chen et al. (2019b) \\
\hline \multirow[t]{2}{*}{ Injection } & Guanxining injection & Myocardial ischemia-reperfusion, $\mathrm{CHD}$, angina pectoris, ischemic stroke & Xiao et al. (2021) \\
\hline & Danshen ligustrazin for injection & Myocardial ischemia, cerebral ischemia-reperfusion injury & Huang et al. (2016) \\
\hline
\end{tabular}

test (PADT), and gelsolin to evaluate the therapeutic effect of postoperative antiplatelet aggregation. It was found that the differences of CD65p, CD63, PADT, and gelsolin before and after operation in the TMP treatment group was greater than in the control group, which showed that TMP could significantly inhibit platelet activation. Wang et al. (2016) used TMP in the treatment of allergic asthma rats induced by ovalbumin and found that the adhesion of platelet to HUVECs was inhibited by TMP, and the expression of two adhesion molecules, vWF and fibronectin, expressed in endothelial cells, was reduced in the asthmatic rats 


\section{Chuanxiong in Cardio-cerebrovascular diseases}

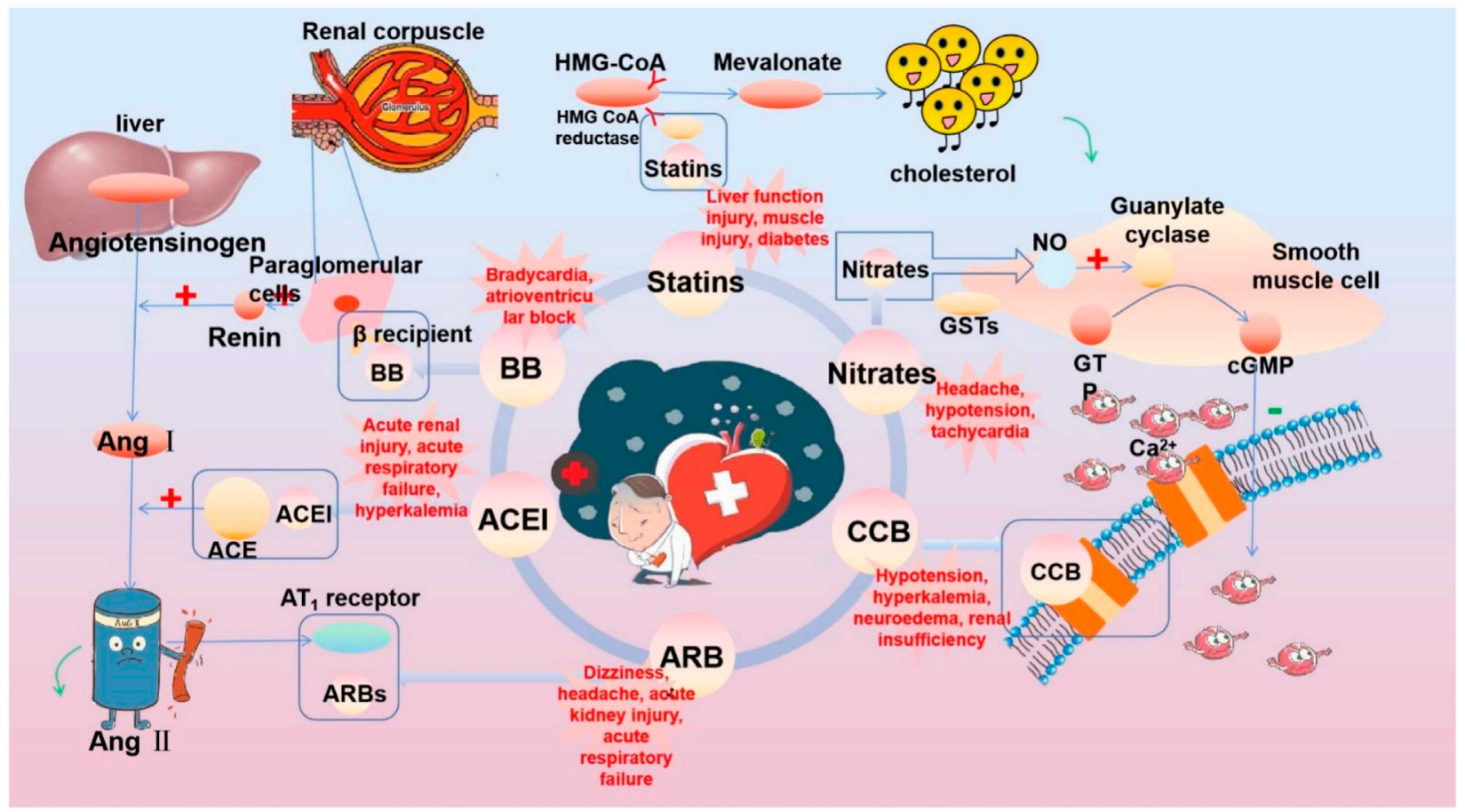

FIGURE 3 | Commonly used drugs for CVD and their mechanisms (the green symbol indicates the effect after administration, and the red symbol indicates the pathological condition. Commonly used drugs for CVDs include statins, BB, ACEI, ARBs, CCB, and nitrates. Angiotensin produced by the liver is converted to Ang I under the action of renin secreted by juxtaglomerular cells, and then to Ang II under the action of ACE. Ang II can bind to AT1 receptor and produce vasoconstriction. BB can bind to $\beta$ receptor of adjacent glomerular cells and reduce the secretion of renin. ACEl can inhibit ACE and reduce Ang II. ARBs can bind to AT1 receptor and competitively inhibit the binding of Ang II to AT1 receptor. BB, ACEI, and ARBs play a role in the renin-angiotensin system, thereby inhibiting vasoconstriction, reducing blood volume, and lowering blood pressure. CCB can directly block the $\mathrm{Ca}^{2+}$ channel on the endothelial cell membrane and reduce $\mathrm{Ca}^{2+}$ influx, thereby reducing blood pressure and myocardial contractility. HMG-CoA is transformed into mevalonate by HMG-CoA reductase, and then into cholesterol. Statins can significantly reduce blood cholesterol and LDL by inhibiting HMG-CoA reductase, thus achieving the effect of lowering blood lipid. Nitrates catalyzed the release of NO in the smooth muscle cells by GSTs, and NO activates guanylate cyclase, increasing the content of intracellular second messenger cGMP, and then activating cGMP-dependent protein kinase, which reduces intracellular $\mathrm{Ca}^{2+}$ release and extracellular $\mathrm{Ca}^{2+}$ influx and relaxes smooth muscle cells).

treated with TMP. It is confirmed that TMP markedly inhibited platelets activation and aggregation, and promoted blood circulation, and platelet adhesion was significantly attenuated. Zhang et al. (2020a) demonstrated that TMP can partially inhibit the p38MAPK and NF- $\mathrm{BB}$ signaling pathways, thereby reducing platelet adhesion of mouse micro-VECs induced by oxygen-glucose deprivation/reoxygenation injury. Choi et al. (2018) through the study of ferulic acid in in vivo and in vitro experiments found that ferulic acid can inhibit platelet aggregation to play a role in weakening platelet activation by stimulation and can play an antithrombotic role in the acute thromboembolism model.

\section{LIGUSTICUM CHUANXIONG HORT. IN THE TREATMENT OF CARDIO-CEREBROVASCULAR DISEASES}

Under the guidance of the current situation that CX is widely used in CVDs, the effects of CX on hypertension, CHD, AS, heart failure, cerebral hemorrhage, and cerebral ischemia are described.
Supported by clinical data and combined with network pharmacology research, the signaling pathway and mechanism of CX in the treatment of CVDs are constantly explored to promote its more comprehensive application.

\subsection{Cardiovascular Disease \\ 5.1.1 Hypertension}

According to the American Heart Association, hypertension is one of the five major risk factors for disease burden in areas other than Oceania and the eastern, central, and western parts of subSaharan Africa (Virani et al., 2021). It is one of the most important risk factors for CVDs and is closely related to stroke, heart failure, and other CVDs. Currently, the prevalence rate of hypertension in China is $50 \%$ and the United States is $46 \%$ (Chen et al., 2019a).

Through the analysis of network pharmacology of CX and hypertension, it was found that CX could be based on the calcium signaling, VEGF signaling, PI3K-Akt signaling, cGMP-PKG signaling, TNF signaling, and estrogen, insulin resistance, and prostate cancer pathways. CX can be involved in the treatment of 
hypertension by blocking vasoconstrictor molecules, increasing the number of smooth muscle cells, reducing the number of intracellular $\mathrm{Ca}^{2+}$ and other mechanisms (Yan et al., 2020).

According to the statistics, Tian et al. (2021) analyzed the clinical data of TCM in the treatment of hypertension patients and found that among the hypertension diseases with different syndrome types, CX was used the most frequently, and according to different syndrome types, it was combined with Gastrodia elata Blume (Tianma, TM), Dioscorea opposita Thumb. (Shanyao, SY), DG, Pinellia ternate (Thunb.) Breit. (Banxia, BX), etc.

\subsubsection{Coronary Heart Disease}

$\mathrm{CHD}$, also known as coronary atherosclerotic heart disease, is a kind of heart disease caused by myocardial ischemia, hypoxia, or necrosis caused by coronary artery stenosis, spasm, or occlusion (Therapy, 2021). Angina pectoris refers to chest discomfort caused in the heart (Joseph and Colin, 2020), which is one of the common complications of patients with CHD. About $80 \%$ of patients with CHD will have angina pectoris (Wei, 2021).

Through the analysis of network pharmacology of CX in the treatment of CHD, seven compounds were selected from CX. It was found that they could be used in 31 targets such as vascular hemophiliac molecule, coagulation factor 2, transmembrane receptor protein 1 , cardiac cell enhancement factor $2 \mathrm{~A}$, SOD 1 , nitric oxide synthase 2 , etc. Based on these targets, CX can play the role of anti-oxidation, anti-inflammation, anticoagulation, promoting angiogenesis, dilating blood vessels, regulating blood pressure, and other functions to realize the treatment of CHD (Zhao-et al., 2019).

Bi et al. (2020) investigated the clinical medication data of 1986 patients with CHD in 11 provinces, cities, and autonomous regions of China. Among them, drugs for property of activating blood and resolving stasis were used 2,173 times. In addition, in the application of single drug in the treatment of $\mathrm{CHD}$, the frequency of use of CX reached 447 times, $56.58 \%$, second only to Danshen. Ma (2018b) investigated the clinical efficacy of CX injection in patients with $\mathrm{CHD}$ and angina pectoris. The control group received angiotensin II receptor antagonists (ARBs), aspirin, nitrate drugs, and $\beta$-receptor blockers (BB), while the observation group was given ligustrazine injection on the basis of the control group. The clinical results showed that the frequency and duration of angina pectoris in the observation group were significantly lower than in the control group, and the total effective rate in the observation group (94.44\%) was significantly higher than that of the control group (82.22\%). As far as the clinical data of ligustrazine injection are concerned, they show that ligustrazine injection has a better disease control effect.

\subsubsection{Atherosclerosis}

AS is the main pathological basis of cardiovascular disease. It refers to a progressive pathological process in which the structure or function of the endothelial cells of the large and medium arteries are damaged, the permeability of the intima is increased, and cholesterol and cholesterol lipid accumulate in or under the intima of the artery under the combined action of a variety of risk factors (Ma, 2016). The potential mechanisms include endothelial dysfunction, lipid deposition, OS injury, immune inflammatory response, and platelet migration and aggregation (Xin et al., 2020).

Through the analysis of network pharmacology of CX in the treatment of AS, 20 compounds were screened from CX and 37 targets were found in the treatment of AS. Through KEGG analysis of these targets, it was found that CX could exert anti-inflammatory, anti-OS, protect endothelial cells, inhibit the proliferation and migration of VSMCs, improve vasoconstriction, and inhibit platelet aggregation by affecting 14 pathways, including TNF, insulin resistance, vascular smooth muscle contraction, calcium ion, VEGF, TRP channel regulated by inflammatory mediators, and platelet activation, so as to achieve the therapeutic effect on AS (Tian et al., 2018).

Deng et al. (2017) analyzed the clinical efficacy of Danshen combined with CX in the treatment of elderly patients with AS. The control group was given routine treatment of AS, and the observation group was given Danshen: CX decoction (5:4). The levels of inflammatory factors and blood lipids in the venous blood of the patients were detected after 30 days. The levels of inflammatory factors including C-reactive protein (CRP), IL- $1 \beta$, IL-6, TNF- $\alpha$, monocyte chemotactic protein-1, and blood lipids total, including total cholesterol (TC), triglyceride, high-density lipoprotein cholesterol, and LDL cholesterol in the venous blood of the patients after 30 days were measured. It was found that there was no significant difference in the blood lipid level between the control and observation groups, whereas the inflammatory factor level of the observation group was significantly lower than that of the control group. The data showed that Danshen combined with CX had an obvious anti-infection effect in the treatment of elderly patients with AS and a better disease control effect on patients with AS. Zuo et al. (2020) studied the clinical efficacy of Xingnao Zhitan capsule (including CX) in the treatment of the carotid artery in patients with acute cerebral infarction. During the 3-month treatment, the control group was given atorvastatin calcium tablets and the observation group was given atorvastatin calcium tablets combined with Xingnao Zhitan capsule. After research, it was found that TC and LDL in the observation group were significantly lower than those in the control group, and FIB, D-D, hs CRP, IMT, Crouse scores were significantly improved, and the total effective rate in the observation group $(82.1 \%)$ was significantly higher than that in the control group (60.5\%). According to the analysis of the clinical data, the capsule can control AS by regulating blood lipid and reducing inflammation and plate volume.

\subsubsection{Heart Failure}

Chronic heart failure (CHF) is a clinical syndrome with abnormal cardiac structure and function caused by a variety of risk factors (Jia et al., 2020b). It has the characteristics of high incidence rate, high mortality rate, and high medical expenditure ( $\mathrm{Li}$ et al., 2020b). Only in the United States, heart failure accounted for $10 \%$ of the total medical expenses in medical spending, and patients with heart failure in 2030 are expected to increase to eight million.

Through the analysis of network pharmacology of CX in the treatment of heart failure, it was found that CX could realize the 
therapeutic effect of heart failure through 12 targets, one of which was related to chest and flank prickling pain. Through KEGG enrichment analysis of these targets, it has been found that CX can activate the cancer signaling pathway, apoptosis, HIF-1, and the other signaling pathways to achieve the functions of inhibiting inflammation, regulating apoptosis, and improving vasoconstriction to treat heart failure (Jia et al., 2020a).

Zhang (2019) analyzed the clinical efficacy of Danshen-ligustrazin for injection in the treatment of heart failure. The control group was given conventional treatment methods such as oxygen inhalation, cardiotonic, low salt diet, vasodilation, and bed rest. The observation group was given Danshen-ligustrazin for injection on the basis of the control group. After 14 days of treatment, the relevant levels of the patients were detected. It was found that the left ventricular ejection fraction (LVEF) of the observation group was significantly higher than that of the control group, and the brain natriuretic peptide (BNP) level was significantly lower. The total effective rate in the observation group (90\%) was significantly higher than that in the control group (78\%). Through clinical data analysis, Danshen-ligustrazin for injection can effectively improve cardiac function and hemodynamics and has a good control effect on heart failure. Sui et al. (2020) analyzed the clinical efficacy of Danshen-ligustrazin for injection in the treatment of blood stasis syndrome of CHF. The control group received conventional treatment of heart failure by limiting salt and water, using digitalis preparation, $\mathrm{BB}$, angiotensin converting enzyme inhibitors (ACEI)/ARB, and aldosterone receptor antagonist and diuretic, and the observation group was given Danshen-ligustrazin for injection on the basis of the control group. It was found that compared with the control group, the levels of NT-proBNP and myocardial energy consumption were significantly decreased and LVEF was significantly increased in the observation group. In addition, the total effective rate of the observation group (80\%) was significantly higher than that of the control group (57.17\%). Through the analysis of clinical data, Danshen-ligustrazin for injection can relieve the clinical symptoms of CHF patients with blood stasis and improve cardiac function, so as to play a good therapeutic effect on heart failure.

\subsection{Cerebrovascular Disease}

In 2017, the Cerebrovascular Division of the Neurology Society of the Chinese Medical Association released the "Classification of Cerebrovascular Diseases in China 2015," which explained cerebrovascular diseases and believed that cerebrovascular diseases are transient or permanent neurological dysfunction caused by various risk factors. Stroke is the second leading cause of death worldwide and increases the global medical burden (Shakiba et al., 2021), especially acute cerebrovascular disease, which is a focal vasogenic neurological deficit syndrome that can lead to death or permanent neurological defects (Fan, 2018). Stroke is characterized by high morbidity, high disability, high mortality, and high recurrence rate (Jin et al., 2021), including ischemic cerebrovascular disease and hemorrhagic cerebrovascular disease (Chen et al., 2017b). Ischemic strokes are more common, accounting for $87 \%$ of strokes in the United States. In Asian countries, cerebral hemorrhage accounts for $24-55 \%$ of all strokes, while in China, the rate is $24 \%$, significantly higher than in developed countries (Li, 2019). Ischemic stroke refers to the blood clots in the blood that stop enough blood supply to the brain, and hemorrhagic stroke refers to the primary non-traumatic hemorrhage that cause bleeding within the brain parenchyma of the microvascular burst (Zheng and Deng, 2020). Hemorrhagic stroke is gender related, with women having a higher rate of stroke-related deaths than do men, averaging six out of 10 women (Derek and Hiranmoy, 2020).

\subsubsection{Cerebral Ischemia}

Song et al. (2015) analyzed the material basis and molecular mechanism of CX in the treatment of cerebral ischemia through molecular docking technology. Through molecular docking of 45 components selected from CX with cerebral ischemia target proteins of four existing drugs on the market, it was found that 12 components of CX scored higher than the existing drugs on the market, and ferulic acid scored the highest. Other studies have proven that CX can inhibit the expression of Uba3a, thereby inhibiting the NF- $\mathrm{B}$ signaling pathway and relieving neuron cell damage (Yu et al., 2017). Z-ligustilide nasal administration can prevent cerebral ischemia through the Nrf2 and HSP70 signaling pathways (Li et al., 2017b).

Cheng and Luo (2020) analyzed the clinical effect of TMP on elderly patients with early cerebral ischemia after intracranial aneurysm clipping. The control group was given edaravone injection, and the observation group was given TMP injection. After 14 days of treatment, it was found that the Barthel Index (BI) and SOD level of the observation group were higher than those of the control group, and the NIHSS score and plasma MDA level of the observation group were lower than those of the control group. The clinical data show that TMP can improve OS and reduce rebleeding in elderly patients with early cerebral ischemia after intracranial aneurysm clipping, which has important clinical value.

\subsubsection{Cerebral Hemorrhage}

In the treatment of intracerebral hemorrhage, studies have shown that Danshen-ligustrazin for injection can reduce cell apoptosis by reducing the release of IL- 6 and TNF- $\alpha$, increasing the expression of NOS, decreasing the expression of Caspase-3, and increasing the expression of $\mathrm{Bcl}-2$, thus playing a role in the treatment of intracerebral hemorrhage (Zhang et al., 2018a).

Sun et al. (2008) analyzed the clinical efficacy of ligusticum (sodium ferulic acid) for intracerebral hemorrhage. The control group was given routine treatments such as dehydration, brain cell activator, regulation of blood pressure and blood glucose, and management of stress complications, and the observation group was given intravenous infusion of ligusticum on the basis of the control group. Zhao (2020) analyzed the clinical efficacy of Taoren-Chuanxiong decoction on cerebral hemorrhage. The control group was treated with Piracetam tablet, and the observation group was treated with Taoren-Chuanxiong decoction on the basis of the control group. It was found that the whole blood high-shear viscosity, whole blood low-shear 
viscosity, plasma viscosity, and HCT of the observation group were significantly lower than those of the control group, and the NHISS, FMA, and BI scores of the patients were better than those of the control group, and the total effective rate in the observation group $(88.89 \%)$ was significantly higher than that in the control group $(71.11 \%)$. This shows that Taoren-Chuanxiong decoction has an obvious improvement effect on the nerve function defect and hemodynamics of the patients and can effectively control the condition of the patients with cerebral hemorrhage.

\section{COMBINED APPLICATION OF LIGUSTICUM CHUANXIONG HORT. AGAINST CARDIO-CEREBROVASCULAR DISEASE}

\subsection{Study on the mechanism of compound containing Ligusticum chuanxiong Hort.}

So far, CX has been widely used in cardiovascular and cerebrovascular diseases and together with a variety of drugs, which provide a certain idea and feasibility for the prevention and treatment of CVDs and also a new direction for drug research and development. Modern pharmacological studies have found that it can reduce arterial resistance, increase cerebral blood flow, improve microcirculation, reduce capillary permeability, and has a protective effect on brain injury, so it plays an important role in the prevention and treatment of CVDs (Zeng et al., 2013). In previous studies, CX and other drug combinations were collected and identified for CVDs therapy, in order to provide theoretical support for the subsequent studies on CX resistance to CVDs (Table 2).

\subsection{Modern Application of Preparations Containing Ligusticum chuanxiong Hort.}

Compared with chemical medicine, natural medicine has the advantages of less side effects, multiple links, and multiple targets. Its preparation into capsules, granules, pills, tablets, oral liquid, injection, and other dosage forms is conducive to improve its bioavailability, enhances the convenience in its production, transportation, taking, carrying, and storage, and makes it better in playing its pharmacodynamic role. A total of 1640 modern preparations have been collected in the Chinese Pharmacopoeia, of which $9.21 \%$ are CX (Li, 2017). This article summarizes the current modern preparations containing CX, and their applications in CVDs are counted, in order to provide some reference for follow-up research of other scholars (Table 3).

\section{THE SECURITY TOXICITY OF LIGUSTICUM CHUANXIONG HORT.}

At present, the clinical treatment of CVDs still mainly uses $\mathrm{BB}$, calcium channel blockers (CCB), ACEI, ARBs, statins, nitrates, etc (Liu et al., 2019b). In a survey of patients with CHD in 24 European countries, the European Heart Association found that of the cardioprotective drugs, $\mathrm{BB}$ accounted for $82.6 \%$, ACEI/ ARBs for $75.1 \%$, and statins for $85.7 \%$ (Kornelia et al., 2016). Statin is the first ideal choice to treat hypercholesterolemia. In addition, drugs such as ACEI, ARBs, BB, CCB, and nitrate are also commonly used for CVDs. However, while it plays a therapeutic role in several ways, it affects normal cells, proteins, and factors, resulting in various toxic effects and side effects (Figure 3); for example, nearly one-third of statin users generally have side effects depending on the dose, and the risk of myopathy is higher at higher doses (Li et al., 2015a).

CAM has gained popularity among health professionals over the past few years because of its preventive mechanisms against the side effects of chemotherapy drugs. On the basis of several acute toxicology studies, CX was found to be highly safe in both gavage experiments and intraperitoneal injection. In the CX gavage experiment, mice's $\mathrm{LD}_{50}$ is $7.26 \mathrm{~g} / \mathrm{kg}$, or 1460 times the maximum clinical dose of $\mathrm{CX}$. In the $\mathrm{CX}$ intraperitoneal injection, mice's $\mathrm{LD}_{50}$ is $2.52 \mathrm{~g} / \mathrm{kg}$, which is equivalent to 5,091 times of the maximum clinical dose of CX (Ran, 2012). Xia et al. (2018) found that under the 16-fold clinical dose, the decoction of CX may increase mouse fetal stillbirth and absorption fetus, cause sternum and limb bone deformities, and have weak embryotoxicity. Zhang (2014) measured that the LD50 of mice was $1594.92 \mathrm{mg} / \mathrm{kg}$ after a single intragastric administration of CX volatile oil. In addition, CX has few adverse reactions in clinical application, mainly facial flushing and emotional agitation, which can improve without additional intervention (Pan, 2012). It is demonstrated that CX is highly safe at normal clinical doses.

The above results are mainly based on the preclinical and clinical research of CX. In life, CX is often boiled together with beef and mutton as health food (Donkor et al., 2016). In Yunnan, China, the tender stems and leaves of CX are often eaten as vegetables (Yang et al., 2013). The characteristics of high safety of CX were explained from the medicinal and edible perspective. However, although natural drugs are generally considered to be safe and non-toxic, they have the characteristics of "multi-links and multi-targets," they inevitably cause us to think about whether they will produce unknown or uncontrollable effects, and they affect the uptake and transport of drugs and then cause damage. Therefore, as a "homology medicine and food" drug, when evaluating the safety of CX, we must pay attention to being rigorous and objective. We cannot simply identify its high safety. We should study the potential safety hazards from the whole and in part.

\section{SUMMARY AND PROSPECT}

As a natural medicine, CX has less toxic and side effects than other artificial drugs. It has rich effective ingredients, has extensive pharmacological effects, and can be used in many parts, with good quality and at low price. Based on these characteristics, the rhizomes, leaves, and fibrous roots of CX can be used as food and medicine. However, at present, the rhizomes are mostly used and the aboveground parts are abandoned, which not only causes a waste of resources but 
also makes it difficult to control its quality. At the same time, due to its planting, harvesting, processing, and other links, there are many influencing factors resulting in the differences in its efficacy, including soil fertility, water and nutrients in growth, harvesting method, season, origin, and so on, make its quality differences. Therefore, the establishment of strict quality control and safety testing means can not only strengthen the utilization of resources but also realize its industrialization and internationalization, realize the unified control of CX's quality, and enhance its safety identification. With the development of drug safety research, metabolomics can be used to identify related biomarkers, monitor the overall dynamic changes of metabolites, judge the effect of drugs on the target site, and then realize the scientific prediction of drug safety. In addition, quality markers can also be used to control drug quality to avoid the impact of evaluation based on single component or multiple component indexes on the overall quality monitoring. At present, the safety study of CX is not perfect, so it can be studied by means of metabonomics, equivalent component group discovery technology, serum pharmacochemistry, network pharmacology, quality markers, etc., to provide a basis for safety evaluation and quality control of CX.

Finally, CX has rich pharmacological effects and a wide range of applications. Its basic research is abundant, mainly in the field of CVDs. However, current studies on the direct target and mechanisms of CVDs treatment are still lacking. It requires researchers to carry out more in-depth research from the molecular, cellular, and animal perspectives and provides more comprehensive treatment ideas for CX in the treatment of CVDs through the combination of molecular biology, genomics, metabonomics, and other methods which further promote the progress of human health career. At the same time, in order to optimize the efficacy of CX, studies can also be carried out from

\section{REFERENCES}

Acharya, B., Chaijaroenkul, W., and Na-Bangchang, K. (2021). Therapeutic Potential and Pharmacological Activities of $\beta$-eudesmol. Chem. Biol. Drug Des. 97, 984-996. doi:10.1111/cbdd.13823

Bao, Y. R., Wang, S., Yang, X. X., Li, T. J., and Shengmeng, X. (2019). Extraction and Purification Process of Chuanxiong Phenolic Acid and its Effects on Hypoxic Nerve Cell Injury. Herald Med. 38, 1199-1203. doi:10.3870/ j.issn.1004-0781.2019.09.018

Bhandarkar, N. S., Brown, L., and Panchal, S. K. (2018). Chlorogenic Acid Attenuates High-Carbohydrate, High-Fat Diet-Induced Cardiovascular, Liver, and Metabolic Changes in Rats. Nutr. Res. 62, 78-88. doi:10.1016/ j.nutres.2018.11.002

Bi, Y. F., Wang, X. L., Zhao, Z. Q., Hou, Y. Z., Wang, C., Zhao, G. Y., et al. (2020). Investigation on Clinical Application of Traditional Chinese Medicine in 1986 Patients with Coronary Heart Disease. Chin. J. Integr. Med. Cardio-Cerebrovasc. Dis. 18, 2959-2962+2973. doi:10.12102/j.issn.1672-1349.2020.18.004

Bo, C. J., Jing, Y., Fu, W. P., Ming, Z. L., Lin, H. B., and Chen, D. J. (2021). Study on Neuroprotective Mechanism of Ligustilide-Mediated PI3K/AKT/ mTOR Signal Pathway in Rats with Cerebral Ischemia-Reperfusion Injury. J. N. Sichuan Med. Coll. 36, 826-831. doi:10.3969/j.issn.10053697.2021.07.003

Boo, J. J., Yeong, J. S., Ho, P. J., Rak, L. J., Won, Y. K., Tae, K. S., et al. (2009). Antioxidant Activity in Essential Oils of Cnidium Officinale Makino and Ligusticum Chuanxiong Hort and Their Inhibitory Effects on DNA Damage the perspectives of preparation and drug delivery way. The preparation of modern new nanometer preparation and the expansion of drug delivery way can improve drug loading, optimize drug delivery efficiency, solve the problems of firstpass effect and blood-brain barrier, achieve more efficient accurate effects, and promote modern CX research from the CVDs point of view.

\section{AUTHOR CONTRIBUTIONS}

DL, NL, CZ, and MY designed the study; YL, SY, AS, JyW, JgW, $\mathrm{XL}, \mathrm{SL}$, and YZ supplied materials and analytic tools; DL, YL, and SL wrote the article.

\section{FUNDING}

This work was supported by the Xinglin Scholar Discipline Promotion Talent Program of Chengdu University of Traditional Chinese Medicine (No. XGZX 2010); national talent project of traditional Chinese medicine characteristic technology inheritance (No. T20194828003); major science and technology research and development projects in Jiangxi Province (No. 20194ABC28009); and 2021 "three districts" talent plan (No. 319021057).

\section{SUPPLEMENTARY MATERIAL}

The Supplementary Material for this article can be found online at: https:/www.frontiersin.org/articles/10.3389/fphar.2021.832673/ full\#supplementary-material

and Apoptosis Induced by Ultraviolet B in Mammalian Cell. Cancer Epidemiol. 33, 41-46. doi:10.1016/j.canep.2009.04.010

Burcu, G., Osman, C., Aslı, C., Namik, O., and Neșe, B. (2016). The Protective Cardiac Effects of B-myrcene after Global Cerebral Ischemia/reperfusion in C57BL/J6 Mouse. Acta Cir. Bras. 31, 456-462. doi:10.1590/S0102865020160070000005

Cai, X. X., Chen, Z., Pan, X. K., Xia, L., Chen, P., Yang, Y., et al. (2014). Inhibition of Angiogenesis, Fibrosis and Thrombosis by Tetramethylpyrazine: Mechanisms Contributing to the SDF-1/CXCR4 axis. PLoS One 9, e88176. doi:10.1371/ journal.pone.0088176

Chen, C., Guo, C., Gao, J., Shi, K. F., Cheng, J. T., Zhang, J., et al. (2019a). Vasorelaxant and Antihypertensive Effects of Tianshu Capsule on Rats: An In Vitro and In Vivo Approach. Biomed. Pharmacother. 111, 188-197. doi:10.1016/j.biopha.2018.12.061

Chen, C., Wang, F. Q., Xiao, W., Xia, Z. N., Hu, G., Wan, J. B., et al. (2017a). Effect on Platelet Aggregation Activity: Extracts from 31 Traditional Chinese Medicines with the Property of Activating Blood and Resolving Stasis. J. Tradit. Chin. Med.37, 64-75. doi:10.1016/s0254-6272(17)30028-6

Chen, G., Wu, L., and Deng, C.-Q. (2011). The Effects of BuYang HuanWu Decoction and its Effective Components on Proliferation-Related Factors and ERK1/2 Signal Transduction Pathway in Cultured Vascular Smooth Muscle Cells. J. Ethnopharmacol. 135, 7-14. doi:10.1016/j.jep.2011.02.011

Chen, H. C., Chen, L. L., and Liu, T. J. (2019b). The Effect of Tongtian Oral Liquid Combined with Bubphthalide Sodium Chloride Injection in the Treatment of Acute Cerebral Infarction. Pract. Clin. J. Integr. Tradit Chin. West. Med. 19, 97-99. doi:10.13638/j.issn.1671-4040.2019.10.048 
Chen, Y., Hu, F. Y., and Wu, B. (2017b). Interpretation of "Chinese Classification of Cerebrovascular Diseases (2015). Chin. J. Contemp. Neurol. Neurosurg. 17, 865-868. doi:10.3969/j.issn.1672-6731.2017.12.002

Chen, Z.-Z., Gong, X., Guo, Q., Zhao, H., and Wang, L. (2019c). Bu Yang Huan Wu Decoction Prevents Reperfusion Injury Following Ischemic Stroke in Rats via Inhibition of HIF-1 $\alpha$, VEGF and Promotion $\beta$-ENaC Expression. J. Ethnopharmacol. 228, 70-81. doi:10.1016/j.jep.2018.09.017

Chen, Z. J., Zhang, C., Gao, F., Fu, Q., Fu, C. M., He, Y., et al. (2018). A Systematic Review on the Rhizome of Ligusticum Chuanxiong Hort. (Chuanxiong). Food Chem. Toxicol. 119, 309-325. doi:10.1016/j.fct.2018.02.050

Chen, Z. M., Hu, L., Liao, Y. J., Zhang, X., Yang, Z., Hu, C. J., et al. (2020). Different Processed Products of Curcumae Radix Regulate Pain-Related Substances in a Rat Model of Qi Stagnation and Blood Stasis. Front. Pharmacol. 11, 242. doi:10.3389/fphar.2020.00242

Cheng, F., and Luo, C. (2020). Clinical Observation of Ligustrazine on Elderly Patients with Early Cerebral Ischemia after Intracranial Aneurysm Clipping. Chin. J. Health Lab. Technol. 30, 1104-1106. CNKI:SUN:ZWJZ.0.2020-09-025.

Cheng, Y. S., Cheng, X. X., Zhao, Y. C., and Zhao, H. (2019). Effect of Xiaoxuming Decoction on Acute Cerebral Infarction and Effect on Levels of SOD, MCP-1 and BDNF. Chin. Arc Tradit Chin. Med. 37, 435-437. doi:10.13193/j.issn.16737717.2019.02.045

Choi, J.-H., Park, J.-K., Kim, K.-M., Lee, H.-J., and Kim, S. (2018). In Vitro and In Vivo Antithrombotic and Cytotoxicity Effects of Ferulic Acid. J. Biochem. Mol. Toxicol. 32 (1), e22004. doi:10.1002/jbt.22004

Davis, N., Koichi, F., Zubaerul, F. M., Zahid, H. M., Hiroki, O., and Toru, N. (2019). Dual Inhibition of NADPH Oxidases and Xanthine Oxidase Potently Prevents Salt-Induced Stroke in Stroke-Prone Spontaneously Hypertensive Rats. Hypertens. Res. 42, 981-989. doi:10.1038/s41440-019-0246-2

Demin, L., Hongyu, J., Wenjing, C., Haijuan, H., and Yi, C. (2018). The Progress of Autophagy and Oxidative Stress in Cardiovascular Diseases. J. Clin. Cardiol. 34, 402-407. doi:10.13201/j.issn.1001-1439.2018.04.021

Deng, M. L., Zheng, W. L., and Ju, L. T. (2017). Clinical Efficacy of Salvia Miltiorrhiza Combined with Ligusticum Chuanxiong in the Treatment of Elderly Patients with Atherosclerosis. Chin. J. Gerontol. 37, 3445-3447. doi:10.3969/j.issn.1005-9202.2017.14.028

Derek, B., and Hiranmoy, D. (2020). Current Advances in Ischemic Stroke Research and Therapies. Biochim. Biophys. Acta Mol. Basis Dis. 1866, 165260. doi:10.1016/j.bbadis.2018.09.012

Donkor, P. O., Chen, Y., Ding, L. Q., and Qiu, F. (2016). Locally and Traditionally Used Ligusticum Species - A Review of Their Phytochemistry, Pharmacology and Pharmacokinetics. J. Ethnopharmacol. 194, 530-548. doi:10.1016/j.jep.2016.10.012

Fan, J. S., Liu, D. N., He, C., Li, X. H., and He, F. T. (2016). Inhibiting Adhesion Events by Panax Notoginseng Saponins and Ginsenoside Rb1 Protecting Arteries via Activation of Nrf2 and Suppression of P38 - VCAM-1 Signal Pathway. J. Ethnopharmacol. 192, 423-430. doi:10.1016/j.jep.2016.09.022

Fan, W. X. (2018). Research Progress on the Mechanism of Ischemic Stroke. J. Chin. Pharm. Univ. 49, 751-759. doi:10.11665/j.issn.1000-5048.20180618

Fang, X., Ma, Q., Zhang, K.-X., Yao, S.-Y., Feng, Y., Jin, Y.-S., et al. (2020). Synthesis of Phthalide Derivatives and Evaluation on Their Antiplatelet Aggregation and Antioxidant Activities. J. Asian Nat. Prod. Res. 22, 1176-1187. doi:10.1080/ 10286020.2019.1681982

Feng, W. H. (2006). Clinical Observation on 32 Cases of Coronary Heart Disease with Angina Pectoris Treated by Guanxin Pill. J. New Chin. Med. 36-37. doi:10.13457/j.cnki.jncm.2006.06.020

Gang, W. (2018). Study on Structural Characteristics of Ligusticum CHUANXIONG in the Prevention and Treatment of Myocardial Ischemia Injury and Biopharmaceutical Properries of CHUANXIONG Lactone Components. Hefei: Anhui University of traditional Chinese Medicine. master.

Gao, J. H., Yu, L., and Wang, C. J. (2019). Cilnical Observation of Daqinjiao Decoction in the Treatment of Cervical Spondylotic Hypertension. Shaanxi J. Tradi Chin. Med. 40, 597-599. doi:10.3969/j.issn.1000-7369.2019.05.015

Gu, J. F., Su, S. L., Guo, J. M., Zhu, Y., Zhao, M., and Duan, J.-A. (2018). Antiinflammatory and Anti-apoptotic Effects of the Combination of Ligusticum Chuanxiong and Radix Paeoniae against Focal Cerebral Ischaemia via TLR4/ MyD88/MAPK/NF- $\kappa B$ Signalling Pathway in MCAO Rats. J. Pharm. Pharmacol. 70, 268-277. doi:10.1111/jphp.12841
Gui, M. T., Xu, L. S., Fu, D. Y., Yao, L., Lu, B., Zhou, X. J., et al. (2016). Application Progress of Yueju Pill in Cardiovascular Disease. People's Milit Sur. 59, 506-507. CNKI:SUN:RMJZ.0.2016-05-044.

Guieu, R., Deharo, J.-C., Maille, B., Crotti, L., Torresani, E., Brignole, M., et al. (2020). Adenosine and the Cardiovascular System: The Good and the Bad. J. Clin. Med. 9, 1366. doi:10.3390/jcm9051366

Guo, M., Liu, Y., and Shi, D. Z. (2016). Cardiovascular Actions and Therapeutic Potential of Tetramethylpyrazine (Active Component Isolated from Rhizoma Chuanxiong): Roles and Mechanisms. Biomed. Res. Inter. 2016, 2430329. doi:10.1155/2016/2430329

Haibo, T., Weiwei, S., Sha, L., Qing, S., Tiangang, Z., Yidan, W., et al. (2021). Molecular Mechanism of Palmitic Acid on Myocardial Contractility in Hypertensive Rats and its Relationship with Neural Nitric Oxide Synthase Protein in Cardiomyocytes. Biomed. Res. Int. 2021, 6657476. doi:10.1155/2021/ 6657476

Han, L., Liu, D.-L., Zeng, Q.-K., Shi, M.-Q., Zhao, L.-X., He, Q., et al. (2018). The Neuroprotective Effects and Probable Mechanisms of Ligustilide and its Degradative Products on Intracerebral Hemorrhage in Mice. Int. Immunopharmacol. 63, 43-57. doi:10.1016/j.intimp.2018.06.045

He, L., Bao, Y. R., Meng, X. S., Wang, S., Li, T. J., and Fu, L. (2018). Potential Mechanism of Chuanxiong Phenolic Acid Components for Rat Migraine by Promoting Blood Circulation and Removing Blood Stasis. Centr South Pharma 16, 45-49. doi:10.7539/j.issn.1672-2981.2018.01.008

He, Y., Gui, S. Q., Huang, X. J., and Zhu, D. L. (2021). Effect of Dl-3-NButylphthalide on the Improvement of Neurological Function in Rats with Traumatic Brain Injury. China Pharmaceuticals 30, 32-35. doi:10.3969/ j.issn.1006-4931.2021.08.009

Heitzer, T., Schlinzig, T., Krohn, K., Meinertz, T., and Münzel, T. (2001). Endothelial Dysfunction, Oxidative Stress, and Risk of Cardiovascular Events in Patients with Coronary Artery Disease. Circulation 104, 2673-2678. doi:10.1161/hc4601.099485

Hintz, K. K., and Ren, J. (2003). Tetramethylpyrazine Elicits Disparate Responses in Cardiac Contraction and Intracellular $\mathrm{Ca}(2+)$ Transients in Isolated Adult Rat Ventricular Myocytes. Vascul. Pharmacol. 40, 213-217. doi:10.1016/ j.vph.2003.08.002

Hirofumi, T., Kazuki, S., Chisa, M.-N., Toshiharu, N., Shunsuke, K., Kazutaka, K., et al. (2017). The Contribution of Inflammation to the Development of Hypertension Mediated by Increased Arterial Stiffness. J. Am. Heart Assoc. 6, e005729. doi:10.1161/JAHA.117.005729

Hu, J. L., Zhi, L., Zhang, L. F., Shi, M. G. H., Ding, J. S., and Yang, S. H. (2016a). Effect of Chaihu Shugan San on NF-Kb, C-FOS and 5-HT in Migraine Rats. Sci. Technol. Engineer 16, 205-210. CNKI:SUN:KXJS.0.2016-12-035.

Hu, R., Wang, J. Y., and Zhou, S. (2017). Effect of Yueju Pill on Protective Mechanism of Experimental Rats with Myocardial Ischemia. Chin. J. Ethnomed Ethnopharm 26, 47-49. CNKI:SUN:MZMJ.0.2017-14-018.

Hu, Y.-Y., Wang, Y., Liang, S., Yu, X.-L., Zhang, L., Feng, L.-Y., et al. (2016b). Senkyunolide I Attenuates Oxygen-Glucose Deprivation/reoxygenationInduced Inflammation in Microglial Cells. Brain Res. 1649, 123-131. doi:10.1016/j.brainres.2016.08.012

Huang, W. D., Yang, Y. F., Zeng, Z., Su, M. L., Gao, Q., and Zhu, B. H. (2016). Effect of Salvia Miltiorrhiza and Ligustrazine Injection on Myocardial Ischemia/ reperfusion and Hypoxia/reoxygenation Injury. Mol. Med. Rep. 14, 4537-4544. doi:10.3892/mmr.2016.5822

Hung, H.-Y., and Wu, T.-S. (2016). Recent Progress on the Traditional Chinese Medicines that Regulate the Blood. J. Food Drug Anal. 24, 221-238. doi:10.1016/j.jfda.2015.10.009

'Izzah Ibrahim, N., Fairus, S., Zulfarina, M. S., and Naina Mohamed, I. (2020). The Efficacy of Squalene in Cardiovascular Disease Risk-A Systematic Review. Nutrients 12, 414. doi:10.3390/nu12020414

Jia, C. X., Chen, J. X., Gao, K., Li, J. Z., Zhang, F. L., Wang, J. P., et al. (2020a). Network Pharmacology of Chuanxiong in the Treatment of Heart Failure. World Chin. Med. 15, 1093-1097. doi:10.3969/j.issn.1673-7202.2020.08.001

Jia, Q. J., Wang, L. R., Zhang, X. N., Ding, Y. J., Li, H., Yang, Y. X., et al. (2020b). Prevention and Treatment of Chronic Heart Failure through Traditional Chinese Medicine: Role of the Gut Microbiota. Pharmacol. Res. 151, 104552. doi:10.1016/j.phrs.2019.104552 
Jiang, F. R., Qian, J. C., Chen, S. Y., Zhang, W. B., and Liu, C. (2011). Ligustrazine Improves Atherosclerosis in Rat via Attenuation of Oxidative Stress. Pharm. Biol. 49, 856-863. doi:10.3109/13880209.2010.551776

Jiang, G. H., Chen, S. L., and Wen, W. (2008). Histology Study on Aerial Parts of Rhizoma Chuanxiong. West. China J. Pharm. Sci. 5, 508-510. doi:10.13375/ j.cnki.wcjps.2008.05.006

Jin, L., Sun, S., Ryu, Y., Piao, Z. H., Liu, B., Choi, S. Y., et al. (2018). Gallic Acid Improves Cardiac Dysfunction and Fibrosis in Pressure Overload-Induced Heart Failure. Sci. Rep. 8, 9302. doi:10.1038/s41598-018-27599-4

Jin, X. L., Chen, H. Z., Shi, H., Fu, K. L., Li, J. W., Tian, L., et al. (2021). Lipid Levels and the Risk of Hemorrhagic Stroke: A Dose-Response Meta-Analysis. Nutr. Metab. Cardiovasc. Dis. : NMCD 31, 23-35. doi:10.1016/j.numecd.2020.10.014

Jin, Y., Wu, L., Tang, Y. P., Cao, Y. J., Li, S. J., Shen, J., et al. (2016). UFLC-Q-TOF/ MS Based Screening and Identification of the Metabolites in Plasma, Bile, Urine and Feces of normal and Blood Stasis Rats after Oral Administration of Hydroxysafflor Yellow A. J. Chromatogr. B Analyt Technol. Biomed. Life Sci. 1012-1013, 124-129. doi:10.1016/j.jchromb.2016.01.023

Joseph, F. T., and Colin, B. (2020). Angina: Contemporary Diagnosis and Management. Heart (British Cardiac Soc.) 106, 387-398. doi:10.1136/ heartjnl-2018-314661

Jun, P., Jiang-Feng, S., Guo-Qin, J., and Zhi-Xue, Y. (2015). Ligustrazine Induces Apoptosis of Breast Cancer Cells In Vitro and In Vivo. \%J Journal of Cancer Research and Therapeutics. J. Cancer Res. Ther. 11, 454-8. doi:10.4103/09731482.147378

Kailin, Y., Liuting, Z., Anqi, G., Yaqiao, Y., Shanshan, W., Jinwen, G., et al. (2021). Exploring the Oxidative Stress Mechanism of Buyang Huanwu Decoction in Intervention of Vascular Dementia Based on Systems Biology Strategy. Oxid. Med. Cel. Longev. 2021, 20218879060. doi:10.1155/2021/8879060

Kang, Q. F., Liu, W. H., Liu, H. X., and Zhou, M. (2015). Effect of Compound Chuanxiong Capsule on Inflammatory Reaction and PI3K/Akt/NF-Kb Signaling Pathway in Atherosclerosis. Evid Based. Complement. Altern. Med. : eCAM 2015, 584596. doi:10.1155/2015/584596

Ke, Z. C., Wang, G., Yang, L., Qiu, H. H., Wu, H., Du, M., et al. (2017). Crude Terpene Glycoside Component from Radix Paeoniae Rubra Protects against Isoproterenol-Induced Myocardial Ischemic Injury via Activation of the PI3K/ AKT/mTOR Signaling Pathway. J. Ethnopharmacol. 206, 160-169. doi:10.1016/ j.jep.2017.05.028

Khoshnazar, M., Parvardeh, S., and Bigdeli, M. (2020). Alpha-pinene Exerts Neuroprotective Effects via Anti-inflammatory and Anti-apoptotic Mechanisms in a Rat Model of Focal Cerebral Ischemia-Reperfusion. J. Stroke Cerebrovasc. Dis. 29, 104977. doi:10.1016/ j.jstrokecerebrovasdis.2020.104977

Kim, J. H., Kim, J.-K., Ahn, E.-K., Ko, H.-J., Cho, Y.-R., Lee, C. H., et al. (2015). Marmesin Is a Novel Angiogenesis Inhibitor: Regulatory Effect and Molecular Mechanism on Endothelial Cell Fate and Angiogenesis. Cancer Lett. 369, 323-330. doi:10.1016/j.canlet.2015.09.021

Koc, K., Geyikoglu, F., Cakmak, O., Koca, A., Kutlu, Z., Aysin, F., et al. (2020). The Targets of $\beta$-sitosterol as a Novel Therapeutic against Cardio-Renal Complications in Acute Renal Ischemia/reperfusion Damage. Naunynschmiedeberg's Arch. Pharmacol. 394, 469-479. doi:10.1007/s00210-02001984-1

Kornelia, K., David, W., Dirk, D. B., Guy, D. B., Lars, R., Catriona, J., et al. (2016). EUROASPIRE IV: A European Society of Cardiology Survey on the Lifestyle, Risk Factor and Therapeutic Management of Coronary Patients from 24 European Countries. Anal. Tech. Biomed. Life Sci. 23, 636-648. doi:10.1177/ 2047487315569401

Krylova, I. B., Selina, E. N., Bulion, V. V., Rodionova, O. M., Evdokimova, N. R., Belosludtseva, N. V., et al. (2021). Uridine Treatment Prevents Myocardial Injury in Rat Models of Acute Ischemia and Ischemia/reperfusion by Activating the Mitochondrial ATP-dependent Potassium Channel. Sci. Rep. 11, 16999. doi:10.1038/s41598-021-96562-7

Labdelli, A., Zemour, K., Simon, V., Cerny, M., Adda, A., and Merah, O. (2019). Pistacia Atlantica Desf., a Source of Healthy Vegetable Oil. Appl. Sci. 9, 2552. doi:10.3390/app9122552

Lai, D. P. (2014). "Application of Ligusticum Chuanxiong in Thailand," in China guangzhou international health conference (International Health Association; Guangdong Health Association; Guangzhou University of Chinese Medicine).
Lan, R., Xiang, J., Wang, G.-H., Li, W.-W., Zhang, W., Xu, L.-L., et al. (2013). XiaoXu-Ming Decoction Protects against Blood-Brain Barrier Disruption and Neurological Injury Induced by Cerebral Ischemia and Reperfusion in Rats. Evid Based. Complement. Altern. Med. : eCAM 2013, 629782. doi:10.1155/2013/ 629782

Lee, J.-J., Hsu, W.-H., Yen, T.-L., Chang, N.-C., Luo, Y.-J., Hsiao, G., et al. (2011). Traditional Chinese Medicine, Xue-Fu-Zhu-Yu Decoction, Potentiates Tissue Plasminogen Activator against Thromboembolic Stroke in Rats. J. Ethnopharmacol. 134, 824-830. doi:10.1016/j.jep.2011.01.033

León, A., Del-Ángel, M., Ávila, J. L., and Delgado, G. (2017). Phthalides: Distribution in Nature, Chemical Reactivity, Synthesis, and Biological Activity. Prog. Chem. Org. Nat. Prod. 104, 127-246. doi:10.1007/978-3-31945618-8_2

Li, B., Mao, X. M., and Mao, J. Y. (2005). Clinical Observation of Zhengxintai Granule in Treating Angina Pectoris of Coronary Heart Disease. Tianjin J. Tradit Chin. Med. 2005, 294-296. doi:10.3969/j.issn.1672-1519.2005.04.011

Li, C.-S., Qu, Z.-Q., Wang, S.-S., Hao, X.-W., Zhang, X.-Q., Guan, J., et al. (2011). Effects of Suxiao Jiuxin Pill (See Test) on Oxidative Stress and Inflammatory Response in Rats with Experimental Atherosclerosis. J. Tradit. Chin. Med. 31, 107-111. doi:10.1016/s0254-6272(11)60022-8

Li, D., Kim, R., Mcarthur, E., Fleet, J. L., Bailey, D. G., Juurlink, D., et al. (2015a). Risk of Adverse Events Among Older Adults Following Co-prescription of Clarithromycin and Statins Not Metabolized by Cytochrome P450 3A4. Can. Med. Assoc. J. 187, 174-180. doi:10.1503/cmaj.140950

Li, D. Y., and Yu, Z. B. (2020). Analysis of Import \& Export of Chinese Medicinal Materials in First Half of 2020. Mod. Chin. Med. 22, 12-15. doi:10.13313/ j.issn.1673-4890.20200921001

Li, G. H., Ji, P. C., and Wang, Y. J. (2019). Effect of Xinnaokang Capsule on Hemorheology and Serum Cytokines in Patients with Chronic Stable Angina Pectoris. Chin. J. Coal Ind. Med. 22, 191-194. doi:10.11723/mtgyyx.10079564.201902016

Li, H. B., and Chen, F. (2004). Preparative Isolation and Purification of Chuanxiongzine from the Medicinal Plant Ligusticum Chuanxiong by HighSpeed Counter-current Chromatography. J. Chromatogr. A. 1047, 249-253. doi:10.1016/j.chroma.2004.07.006

Li, J., Wu, Y. S., and Qiu, S. X. (2017a). Research Progress on Polysaccharide from Ligusticum Chuanxiong Hort. Anim. Husb. Feed Sci 38, 71-72. doi:10.16003/ j.cnki.issn1672-5190.2017.05.017

Li, J., Yu, J., Ma, H., Yang, N., Li, L., Zheng, D.-D., et al. (2017b). Intranasal Pretreatment with Z-Ligustilide, the Main Volatile Component of Rhizoma Chuanxiong, Confers Prophylaxis against Cerebral Ischemia via Nrf2 and HSP70 Signaling Pathways. J. Agric. Food Chem. 65, 1533-1542. doi:10.1021/acs.jafc.6b04979

Li, L.-L., Liu, Y.-R., Sun, C., Yan, Y.-G., Tang, Z.-S., Sun, J., et al. (2020a). Taorendahuang Herb Pair Reduces Eicosanoid Metabolite Shifts by Regulating ADORA2A Degradation Activity in Ischaemia/reperfusion Injury Rats. J. Ethnopharmacol. 260, 113014. doi:10.1016/j.jep.2020.113014

Li, L. J. (2017). Studies on the Chemical Constituents of Ligusticum Chuanxiong. Tianjin: Tianjin University. master.

Li, L., Yang, N., Nin, L., Zhao, Z. L., Chen, L., Yu, J., et al. (2015b). Chinese herbal medicine formula tao hong si $\mathrm{Wu}$ decoction protects against cerebral ischemiareperfusion injury via PI3K/Akt and the Nrf2 signaling pathway. J. Nat. Med. 69, 76-85. doi:10.1007/s11418-014-0865-5

Li, W. X., Tang, Y. P., Chen, Y. Y., and Duan, J.-A. (2012). Advances in the Chemical Analysis and Biological Activities of Chuanxiong. Molecules (Basel, Switzerland) 17, 10614-10651. doi:10.3390/molecules170910614

Li, Y. Q. (2019). Analysis of Drug Use Rules Os TCM for Cerebral Edema after Cerebral Hemorrhage Based on Data Mining. Guangzhou: Guangzhou University of traditional Chinese Medicine. master.

Li, Y., and Wang, D. C. (2019). Efficacy of An'Gong Jiangya Wan on Clinical Symptoms of Blood Pressure Fluctuations in Patients with Hypertension. Clini J. Chin. Med. 11, 71-73+76. doi:10.3969/j.issn.1674-7860.2019.07.027

Li, Y., Zhang, X. H., Chen, X. X., Chen, D. Z., Yu, Q., Yang, S. L., et al. (2020b). Chinese Herbal Preparations for Chronic Heart Failure: Study Protocol for an Umbrella Review of Systematic Reviews and Meta-Analyses. Medicine 99, e18966. doi:10.1097/MD.0000000000018966

Li, Z. Q., Zong, S. B., Zhou, J., Wang, Z. Z., and Xiao, W. (2016). A Comparison Study of the Difference in Effect between Adjusted XiaoShuan TongLuo and 
Marketed XiaoShuan TongLuo Tablets on Rats with Focal Cerebral Ischemia. Anhui Med. Pharm. J. 20, 1250-1253. doi:10.3969/j.issn.1009-6469.2016.7.007

Lian, Y., Xia, X., Zhao, H., and Zhu, Y. (2017). The Potential of Chrysophanol in Protecting against High Fat-Induced Cardiac Injury through Nrf2-Regulated Anti-inflammation, Anti-oxidant and Anti-fibrosis in Nrf2 Knockout Mice. Biomed. Pharmacother. 93, 1175-1189. doi:10.1016/j.biopha.2017.05.148

Lim, C., Lim, S., Lee, B., Kim, B., and Cho, S. (2017). Effect of Methanol Extract of Salviae Miltiorrhizae Radix in High-Fat Diet-Induced Hyperlipidemic Mice. Chin. Med. 12, 29. doi:10.1186/s13020-017-0150-0

Lima, G. F., Lopes, R. D. O., Mendes, A. B. A., Brazão, S. C., Autran, L. J., Motta, N. a. V., et al. (2020). Inosine, an Endogenous Purine Nucleoside, Avoids Early Stages of Atherosclerosis Development Associated to eNOS Activation and P38 MAPK/NF-kB Inhibition in Rats. Eur. J. Pharmacol. 882, 173289. doi:10.1016/ j.ejphar.2020.173289

Lin, D. F., Wang, L. L., Yan, S. Q., Zhang, Q., Zhang, J. H., and Shao, A. W. (2019). The Role of Oxidative Stress in Common Risk Factors and Mechanisms of Cardio-Cerebrovascular Ischemia and Depression. Oxid. Med. Cel. Longev. 2019, 2491927. doi:10.1155/2019/2491927

Liu, F. H., Chen, S. J., and Juanni, W. (2017a). Study on the Computer Virtual Screening of Antithrombotic Active Ingredients in Chuanxiong Rhizoma. Chin. Pharm. 28, 2182-2186. doi:10.6039/j.issn.1001-0408.2017.16.0610.1002/ cav.1776

Liu, G. W., Liu, G., Lei, Z. Y., Zheng, X. L., and Yang, H. J. (2018). Effect of Gexiazhuyu Decoction on Platelet Aggregation Rate and Mace Incidence in Patients with Non ST Segment Elevation Myocardial Infarction after PCI. J. Sichuan Tradit Chin. Med. 36, 68-70. CNKI:SUN:SCZY.0.2018-11-024. doi:10.1097/01.hjh.0000548566.68605.1a

Liu, J. J. (2011). Curative Effect Analysis of Guanxinkang Granule in Treating 146 Cases of Angina Pectoris of Coronary Heart Disease. Chin. Manip Rehab Med. $000,74-75$.

Liu, L., Cheng, Y., and Zhang, H. (2004). Phytochemical Analysis of Antiatherogenic Constituents of Xue-Fu-Zhu-Yu-Tang Using HPLC-DAD-ESIMS. Chem. Pharm. Bull. (Tokyo) 52, 1295-1301. doi:10.1248/cpb.52.1295

Liu, M., Chen, X. T., Ma, J., Hassan, W., Wu, H. L., Ling, J. W., et al. (2017b). $\beta$ Elemene Attenuates Atherosclerosis in Apolipoprotein E-Deficient Mice via Restoring NO Levels and Alleviating Oxidative Stress. Biomed. Pharmacother. 95, 1789-1798. doi:10.1016/j.biopha.2017.08.092

Liu, S. Y., Long, Y., Yu, S., Zhang, D. K., Yang, Q. Y., Ci, Z. M., et al. (2021). Borneol in Cardio-Cerebrovascular Diseases: Pharmacological Actions, Mechanisms, and Therapeutics. Pharmacol. Res. 169, 105627. doi:10.1016/j.phrs.2021.105627

Liu, T. (2020). Identification of Ligusticum Chuanxiong and Analysis of Clinical Safe Medication. Guid Chin. Med. 18, 135-136.

Liu, X., Shan, X. L., Chen, H. H., Li, Z., Zhao, P., Zhang, C., et al. (2019a). Stachydrine Ameliorates Cardiac Fibrosis through Inhibition of Angiotensin II/ Transformation Growth Factor $\beta 1$ Fibrogenic Axis. Front. Pharmacol. 10, 538. doi:10.3389/fphar.2019.00538

Liu, Y. J., Li, Z., Shen, D. D., Song, Y. Q., Huang, M. N., Xue, X. X., et al. (2019b). Adjuvant Treatment of Coronary Heart Disease Angina Pectoris with Chinese Patent Medicine: A Prospective Clinical Cohort Study. Medicine 98, e16884. doi:10.1097/MD.0000000000016884

Liu, Y., Yin, H. J., Jiang, Y. R., Xue, M., Guo, C. Y., Shi, D. Z., et al. (2013). Correlation between Platelet Gelsolin and Platelet Activation Level in Acute Myocardial Infarction Rats and Intervention Effect of Effective Components of Chuanxiong Rhizome and Red Peony Root. Evid Based. Complement. Altern. Med. : eCAM 2013, 985746. doi:10.1155/2013/985746

Liu, Z. Y., Deng, P., and Hu, D. (2012). Modern Clinical Application of Gexia Zhuyu Decoction. Jiangxi Tradit Chin. Med. 43, 75-80. doi:10.3969/j.issn.04119584.2012.01.03410.1002/chin.201210215

Liyan, B., Jin, K. H., Xiongyi, H., Tingwei, Z., Jung, K. S., and Ho, J. M. (2021). Protocatechuic Acid Attenuates Isoproterenol-Induced Cardiac Hypertrophy via Downregulation of ROCK1-Sp1-PKC $\gamma$ axis. Sci. Rep. 11, 17343. doi:10.1038/s41598-021-96761-2

Long, Y., Yang, Q., Xiang, Y., Zhang, Y., and Peng, W. (2020). Nose to Brain Drug Delivery - A Promising Strategy for Active Components from Herbal Medicine for Treating Cerebral Ischemia Reperfusion. Pharmacol. Res. 159, 104795. doi:10.1016/j.phrs.2020.104795

Longzhu, L., Yi, L., Xueyuan, B., Man, X., Xiaojiang, Y., Runqing, X., et al. (2017). Choline Ameliorates Cardiovascular Damage by Improving Vagal Activity and
Inhibiting the Inflammatory Response in Spontaneously Hypertensive Rats. Sci. Rep. 7, 42553. doi:10.1038/srep42553

Luca, L., Fabrizio, M., Jean-Claude, T., Peter, L., and Giovanni, .G., C. (2020). Inflamm-ageing: the Role of Inflammation in Age-dependent Cardiovascular Disease. Eur. Heart J. 41, 2974-2982. doi:10.1093/eurheartj/ehz961

Luo, M., Chen, P.-P., Yang, L., Wang, P., Lu, Y.-L., Shi, F.-G., et al. (2019a). Sodium Ferulate Inhibits Myocardial Hypertrophy Induced by Abdominal Coarctation in Rats: Involvement of Cardiac PKC and MAPK Signaling Pathways. Biomed. Pharmacother. 112, 108735. doi:10.1016/j.biopha.2019.108735

Luo, Z. H., Deng, H. J., Fang, Z. C., Zeng, A., Chen, Y. K., Zhang, W., et al. (2019b). Ligustilide Inhibited Rat Vascular Smooth Muscle Cells Migration via C-Myc/ MMP2 and ROCK/JNK Signaling Pathway. J. Food Sci. 84, 3573-3583. doi:10.1111/1750-3841.14936

Ma, H. Q. (2018a). Effect of Niuhuang Jiangya Capsule Combined with Amlodipine in the Treatment of Primary Hypertension. J. Huaihai Med. 36, 718-719. doi:10.14126/j.cnki.1008-7044.2018.06.034

Ma, Q. (2016). Clinical Study on Distribution of TCM Syndrome Elements and Traditional Chinese Medicine in Atherosclerotic Cardio Cerebrovascular Disease. Beijing: Beijing University of traditional Chinese Medicine. master.

Ma, Y. B., Chen, G. Q., and Ni, Z. H. (2019). Clinical Study on Xueshuan Xinmaining Capsules Combined with Nimodipine in Treatment of Acute Cerebral Infarction. Drugs Clinic 34, 970-974. doi:10.7501/j.issn.16745515.2019.04.018

Ma, Y. G., Zhou, M. S., and Zhang, M. F. (2001). Analysis on the Current Situation and Prospect of Chinese Herbal Medicine export. World Agri 9, 27-28. doi:10.3969/j.issn.1002-4433.2001.09.008

Ma, Y. X. (2018b). Clinical Observation of Ligustrazine Injection in the Treatment of Angina Pectoris of Coronary Heart Disease. Med. Health Care 26, 125-126. doi:10.3969/j.issn. 1004-8650.2018.09.073

Maia-Joca, R.-P., Joca, H. C., Ribeiro, F. J., do Nascimento, R. V., Silva-Alves, K.-S., Cruz, J. S., et al. (2014). Investigation of Terpinen-4-Ol Effects on Vascular Smooth Muscle Relaxation. Life Sci. 115, 52-58. doi:10.1016/ j.lfs.2014.08.022

Mayra, T.-S., Cirino, D. S. R., Vieira, K. F., Vieira, A. M., Gustavo, M. C., Visconde, B. G., et al. (2015). Knockout of Toll-like Receptors 2 and 4 Prevents Renal Ischemia-Reperfusion-Induced Cardiac Hypertrophy in Mice. PLoS One 10, e0139350. doi:10.1371/journal.pone.0139350

Mi, Y. H., Wang, M. J., Liu, M. P., Cheng, H., and Li, S. Q. (2020). Pharmacokinetic Comparative Study of GAS with Different Concentration of Tetramethylpyrazine and Ferulic Acid on Liver-Yang Hyperactivity Migraine Model by Blood-Brain Microdialysis Method. J. Pharm. Biomed. Anal. 191, 113643. doi:10.1016/j.jpba.2020.113643

Nam, K. N., Kim, K.-P., Cho, K.-H., Jung, W.-S., Park, J.-M., Cho, S.-Y., et al. (2013). Prevention of Inflammation-Mediated Neurotoxicity by Butylidenephthalide and its Role in Microglial Activation. Cell Biochem Funct 31, 707-712. doi:10.1002/cbf.2959

Ni, X. J., Wong, S. L., Wong, C. M., Chi, W. L., Shi, X. G., Cai, Y. F., et al. (2014). Tetramethylpyrazine Protects against Hydrogen Peroxide-Provoked Endothelial Dysfunction in Isolated Rat Aortic Rings: Implications for Antioxidant Therapy of Vascular Diseases. Evid Based. Complement. Altern. Med. : eCAM 2014, 627181. doi:10.1155/2014/627181

Ning, G., Yuzhen, Z., Lei, L., Li, L., Ping, C., Xuan, Z., et al. (2020). Low Doses of Folic Acid Can Reduce Hyperhomocysteinemia-Induced Glomerular Injury in Spontaneously Hypertensive Rats. Hypertens. Res. 43, 1182-1191. doi:10.1038/ s41440-020-0471-8

Oliviero, O., Giulia, S., Annalisa, C., Patrizia, P., Silvia, U., Francesca, P., et al. (2020). The Positive Association between Plasma Myristic Acid and ApoCIII Concentrations in Cardiovascular Disease Patients Is Supported by the Effects of Myristic Acid in HepG2 Cells. J. Nutr. 150, 2707-2715. doi:10.1093/jn/ nxaa202

Or, T. C., Yang, C. L., Law, A. H., Li, J. C., and Lau, A. S. (2011). Isolation and Identification of Anti-inflammatory Constituents from Ligusticum Chuanxiong and Their Underlying Mechanisms of Action on Microglia. Neuropharmacology 60, 823-831. doi:10.1016/j.neuropharm.2010.12.002

Pan, R., Cai, J., Zhan, L. C., Guo, Y. H., Huang, R.-Y., Li, X., et al. (2017). Buyang Huanwu Decoction Facilitates Neurorehabilitation through an Improvement of Synaptic Plasticity in Cerebral Ischemic Rats. BMC Complement. Altern. Med. 17, 173. doi:10.1186/s12906-017-1680-9 
Pan, X. C. (2012). Clinical Effect of Ligustrazine in the Treatment of Chronic Pulmonary Heart Disease. Chin. Comm. Doc 14, 174.

Pan, X. J., and Liu, H. (2017). The Application Value of Shiquan Dabu Decoction in the Treatment of Chronic Heart Failure. Chin. Comm. Doc 33, 106-107. doi:10.3969/j.issn.1007-614x.2017.34.61

Pan, Z., Duan, F. J., and Wei, X. H. (2007). Protective Effect and Mechanism of Guanxinkang Capsule on Myocardial Injury in Experimental Acute Myocardial Ischemia Rats. Chin. Pharmacol. Bull. 9, 1185-1188. doi:10.3321/j.issn:10011978.2007.09.017

Paoloa, C., Carla, F., Fabiana, M., Sara, C., Mohsen, N., Boris, B., et al. (2020). Trends in Cardiovascular Diseases burden and Vascular Risk Factors in Italy: The Global Burden of Disease Study 1990-2017. Anal. Tech. Biomed. Life Sci. 28, 385-396. doi:10.1177/2047487320949414

Park, M., Choi, S., Kim, S., Kim, J., Lee, D.-K., Park, W., et al. (2019). NF-кBresponsive miR-155 Induces Functional Impairment of Vascular Smooth Muscle Cells by Downregulating Soluble Guanylyl Cyclase. Exp. Mol. Med. 51, 1-12. doi:10.1038/s12276-019-0212-8

Pu, Z.-H., Dai, M., Xiong, L., and Peng, C. (2020a). Total Alkaloids from the Rhizomes of a Review of Chemical Analysis and Pharmacological Activities. Nat. Prod. Res. 9, 1-18. doi:10.1080/14786419.2020.1830398

$\mathrm{Pu}$, Z. H., Dai, M., Peng, C., and Xiong, L. (2020b). Research Progress on Material Basis and Pharmacological Action of Alkaloids from Ligusticum Chuanxiong Hort. Chin. Pharm. 31, 1020-1024. doi:10.6039/j.issn.10010408.2020.08.22

Pu, Z. H., Peng, Y. Z., Peng, C., Liu, J., Xiong, L., and Li, W. B. (2018). Optimization of Extraction Process of Total Phenolic Acids from Ligusticum Chuanxiong Hort. Chin. Tradi Pat Med. 40, 1506-1509. doi:10.3969/j.issn.10011528.2018.07.012

Qiang, W., Ping, Y. Y., Xue, Y., Tao, C. H., Jun, W. C., and Ri, X. (2017). Ligustrazine Inhibits pm2.5-induced Proliferation of Vascular Smooth Muscle Cells by Down Regulating JNK Phosphorylation. Chin. J. Pharmacol. Toxicol. 31, 707-713. doi:10.3867/j.issn.1000-3002.2017.07.002

Qin, K. (2020). Current Situation and Development of Cardiovascular and Cerebrovascular Disease Surveillance in China. Appl. Prevent Med. 26, 265-268. doi:10.3969/j.issn.1673-758X.2020.03.031

Ran, X., Ma, L., Peng, C., Zhang, H., and Qin, L.-P. (2011). Ligusticum Chuanxiong Hort: a Review of Chemistry and Pharmacology. Pharm. Biol. 49, 1180-1189. doi: $10.3109 / 13880209.2011 .576346$

Ran, X. (2012). The Therapeutic Effect of Essential Oil of Ligusticm Chuanxiong Hort. On Human Hypertrophic Scar Nd its Safety Evaluation. Shanghai: East China Normal University. master.

Ren, P., Kang, Q. F., Zhou, M. X., Zhang, L., Li, S. N., and Liu, W. H. (2017). Intervention Effect of Danggui Shaoyao Powder on Atherosclerosis in Mice and Expression of DNA Methyltransferase 1 and PPAR- $\gamma$ the Influence of Expression. Glob. Tradit Chin Med 10, 1328-1332. doi:10.3969/j.issn.16741749.2017.11.009

Ren, Z. Q., Ma, J. H., Zhang, P. H., Luo, A. T., Zhang, S., Kong, L. H., et al. (2012). The Effect of Ligustrazine on L-type Calcium Current, Calcium Transient and Contractility in Rabbit Ventricular Myocytes. J. Ethnopharmacol. 144, 555-561. doi:10.1016/j.jep.2012.09.037

Rhyu, M., Kim, E., and Kim, B. (2004). Nitric Oxide-Mediated Vasorelaxation by Rhizoma Ligustici Wallichii in Isolated Rat Thoracic Aorta. Phytomedicine : Int. J. Phytother. Phytopharmacol. 11, 51-55. doi:10.1078/0944-7113-00334

Sedigheh, A., Ali, N. G., Reza, S. a. M., Amirhossein, S., Atousa, A., Sanaz, A., et al. (2013). Chemical Analysis and Biological Activities of Cupressus Sempervirens Var. Horizontalis Essential Oils. Pharm. Biol. 51, 137-144. doi:10.3109/ 13880209.2012.715168

Shakiba, A., Zahra, S., Samira, A., Tahereh, F., Mahmood, S., Fatemeh, A., et al. (2021). Therapeutic Potential of Saffron ( L.) in Ischemia Stroke. Evid Based. Complement. Altern. Med. : eCAM 2021, 6643950. doi:10.1155/2021/6643950

Shan, F., and Hao, J. D. (2011). The Origin of Rhizoma Chuanxiong. Chin. J. Chin. Mater. Med. 36, 2306-2310. doi:10.4268/cjcmm20111632

Shan, L. N., and Leng, L. (2019). Effect of Xueshuanxinmaining Tablet on Vascular Endothelial Function and Hemorheology in Patients with Coronary Heart Disease and Angina Pectoris. Mod. J. Integr. Tradit Chin. West. Med. 28, 2560-2563. doi:10.3969/j.issn.1008-8849.2019.23.013

Shen, Y.-C., Lu, C.-K., Liou, K.-T., Hou, Y.-C., Lin, Y.-L., Wang, Y.-H., et al. (2015). Common and Unique Mechanisms of Chinese Herbal Remedies on Ischemic
Stroke Mice Revealed by Transcriptome Analyses. J. Ethnopharmacol. 173, 370-382. doi:10.1016/j.jep.2015.07.018

Sheng, H. Z., Qi, X. D., Jun, X. L., Shun, H. C., Min, Z., Jun, C. Y., et al. (2020). Tetramethylpyrazine Ameliorates Lipopolysaccharide-Induced Sepsis in Rats via Protecting Blood-Brain Barrier, Impairing Inflammation and Nitrous Oxide Systems. Front. Pharmacol. 11, 562084. doi:10.3389/fphar.2020.00376

Shengzhong, L., Ying, H., Jun, S., Lulu, L., Hao, M., Li, H., et al. (2019). Downregulation of miRNA-30a Enhanced Autophagy in Osthole-Alleviated Myocardium Ischemia/ reperfusion Injury. J. Cel Physiol, 1-10. doi:10.1002/jcp.28556

Shizu, K., Saki, N., Yutaka, Y., Kang, D., Takeshi, B., and Eiichiro, F. (2012). Metabolic Profiling and Identification of the Genetic Varieties and Agricultural Origin of Cnidium Officinale and Ligusticum Chuanxiong. J. Biosci. Bioeng. 114, 86-91. doi:10.1016/j.jbiosc.2012.02.015

Sirangelo, I., Sapio, L., Ragone, A., Naviglio, S., Iannuzzi, C., Barone, D., et al. (2020). Vanillin Prevents Doxorubicin-Induced Apoptosis and Oxidative Stress in Rat H9c2 Cardiomyocytes. Nutrients 12, 2317. doi:10.3390/nu12082317

Song, T. (2015). Transcriptome Sequncing and Analsis of Rhizme and Leaf in Ligusticum Chuanxiong Hort. Chengdu: Southwest Jiaotong University. master.

Song, X. G., Zhou, W., Cheng, C., Wang, S. M., and Liang, S. W. (2015). Study on Material Base of Ligusticum Wallichii for Treating Brain Ischemia and its Molecular Mechanism Based on Molecular Docking. Chin. J. Chin. Mater. Med. 40, 2195-2198. doi:10.4268/cjcmm20151124

Song, X., Li, Y., Zhao, X., Fan, J. M., and Zhao, J. W. (2018). Influence of Daqinjiao Prescription on Recent Hemorheology Hcy and Neurological Functin in Patients with Acute Cerebral Infarction. Shaanxi J. Tradi Chin. Med. 39, 699-702. doi:10.3969/j.issn.1000-7369.2018.06.005

Stephanieh, R., and Sarahh, W. (2020). Prevention of Premature Cardiovascular Death Worldwide. Lancet (London, England) 395, 758-760. doi:10.1016/S01406736(19)32034-3

Su, Q., Lv, X., and Ye, Z. (2019). Ligustrazine Attenuates Myocardial Injury Induced by Coronary Microembolization in Rats by Activating the PI3K/ Akt Pathway. Oxid. Med. Cel. Longev 2019, 6791457. doi:10.1155/2019/6791457

Sui, Y. B., Sun, B. H., Zhang, D. D., Liu, L., and Zhang, X. (2020). Clinical Study of Danshen Ligustrazine Injection on Patients with Chronic Heart Failure and Blood Stasis Syndrome. J. Emerg. Tradit Chin. Med. 29, 806-809. doi:10.3969/ j.issn.1004-745X.2020.05.015

Sun, Y. M., Lou, J. T., and Huang, G. Q. (2008). Clinical Study on Early Application of Ligusticin in Cerebral Hemorrhage. Chin. J. Chin. Mater. Med. 33, 2545-2548. doi:10.3321/j.issn:1001-5302.2008.21.027

Suručić, R., Kundaković, T., Lakušić, B., Drakul, D., Milovanović, S. R., and Kovačević, N. (2017). Variations in Chemical Composition, Vasorelaxant and Angiotensin I-Converting Enzyme Inhibitory Activities of Essential Oil from Aerial Parts of Seseli Pallasii Besser (Apiaceae). Chem. Biodivers. 14 (5), e1600407. doi:10.1002/cbdv.201600407

Tan, J., Wang, C. Z., Zhu, H. L., Zhou, B. S., Xiong, L. X., Wang, F., et al. (2018). Comprehensive Metabolomics Analysis of Xueshuan Xinmaining Tablet in Blood Stasis Model Rats Using UPLC-Q/TOF-MS. Molecules (Basel, Switzerland) 23, 1650. doi:10.3390/molecules23071650

Tan, Z., Jiang, X. L., Zhou, W., Deng, B., Cai, M., Deng, S. H., et al. (2021). Taohong Siwu Decoction Attenuates Myocardial Fibrosis by Inhibiting Fibrosis Proliferation and Collagen Deposition via TGFBR1 Signaling Pathway. J. Ethnopharmacol. 270, 113838. doi:10.1016/j.jep.2021.113838

Tang, F., Yan, Y.-M., Yan, H.-L., Wang, L.-X., Hu, C.-J., Wang, H.-L., et al. (2021). Chuanxiongdiolides R4 and R5, Phthalide Dimers with a Complex Polycyclic Skeleton from the Aerial Parts of Ligusticum Chuanxiong and Their Vasodilator Activity. Bioorg. Chem. 107, 104523. doi:10.1016/ j.bioorg.2020.104523

Therapy, S. P. T. O. C. a. G. F. P. D. O. C. P. M. (2021). Guidelines for Clinical Application of Chinese Patent Medicine in the Treatment of Coronary Heart Disease (2020 Edition). Chin. J. Integr. Tradit West. Med. 41 (04), 1-27.

Tian, J. F., Lv, S. Z., Song, X. T., Li, L. Z., and Liu, Y. (2018). Study on Action Mechanism of Chuanxiong in Attenuation of Atherosclerosis Based on Network Pharmacology. China Med. 13, 1894-1898. doi:10.3760/j.issn.16734777.2018.12.032

Tian, Y., Zhou, P., Lu, F., Fu, C., Gao, C., Xie, H. T., et al. (2021). Analysis of Clinical Characteristics and Chinese Herbal Medicine Prescription of Hypertension Inpatients Based on Real-World Study. Chin. Tradit Herbal Drugs 52, 469-482. doi:10.7501/j.issn.0253-2670.2021.02.021 
Tong, L. X. (2021). Effects of Levistilide A on Hemorheology and Endothelial Cell Injury Protection in Rats with Blood Stasis. Southwest Medical University. master.

Virani, S. S., Alonso, A., Aparicio, H. J., Benjamin, E. J., Bittencourt, M. S., Callaway, , C. W., et al. (2021). Heart Disease and Stroke Statistics-2021 Update: A Report from the American Heart Association. Circulation 143, e254-e743. doi:10.1161/CIR.0000000000000950

Wang, D. L., Dai, M., and Li, H. K. (2006). Effect of Xuemaitong Capsule on Hemorheology of Experimental Atherosclerosis Rabbits. Chin. J. Tradit Med. Sci. Technol. 1, 28-29. doi:10.3969/j.issn.1005-7072.2006.01.014.k

Wang, F. C., Feng, X. R., Yang, L. X., Li, D. H., and Ma, X. (2018a). Simultaneous Determination of Hydroxysafflor Yellow A and Ferulic Acid in ShuXinNing Tablets by HPLC. Gansu Med. J. 37, 271-272. doi:10.15975/ j.cnki.gsyy.2018.03.031

Wang, F., Jia, J., and Rodrigues, B. (2017a). Autophagy, Metabolic Disease, and Pathogenesis of Heart Dysfunction. Can. J. Cardiol. 33. doi:10.1016/ j.cjca.2017.01.002

Wang, G., Dai, G. L., Song, J., Zhu, M. M., Liu, Y., Hou, X. F., et al. (2018b). Lactone Component from Alleviates Myocardial Ischemia Injury through Inhibiting Autophagy. Front. Pharmacol. 9, 301. doi:10.3389/fphar.2018.00301

Wang, G., Liu, Y., Hou, X. F., Ke, Z. C., Feng, L., and Jia, X. B. (2017b). Prevention Effect of Ligusticum Chuanxiong Extraction against Oxidative Stress Injury Induced by Myocardial Ischemia through Activation of Nrf2 Signaling Pathway. Chin. J. Chin. Mater. Med. 42, 4834-4840. doi:10.19540/ j.cnki.cjcmm.20171010.001

Wang, H., Qiu, L. Z., Ma, Y. K., Zhang, L. S., Chen, L., Li, C. X., et al. (2017c). Naoxintong Inhibits Myocardial Infarction Injury by VEGF/eNOS SignalingMediated Neovascularization. J. Ethnopharmacol. 209, 13-23. doi:10.1016/ j.jep.2017.06.040

Wang, J., Zhang, L., Liu, B., Wang, Q., Chen, Y., Wang, Z., et al. (2018). Systematic Investigation of the Erigeron Breviscapus Mechanism for Treating Cerebrovascular Disease. J. Ethnopharmacol. 224, 429-440. doi:10.1016/ j.jep.2018.05.022

Wang, L., Li, G. Q., Chen, Q. W., and Ke, D. Z. (2015). Octanoylated Ghrelin Attenuates Angiogenesis Induced by oxLDL in Human Coronary Artery Endothelial Cells via the GHSR1a-Mediated NF- $\kappa B$ Pathway. Metabolism 64, 1262-1271. doi:10.1016/j.metabol.2015.07.008

Wang, N. N., Xing, Y. M., Wei, M. L., Li-, R. H., and Chen, J. (2020). Clinical Study on Mailuotong Granules Combined with Urinary Kallidinogenase in Treatment of Cerebral Infarction. Drugs \& Clinic 35, 904-908. doi:10.7501/j.issn.16745515.2020.05.017

Wang, W.-R., Lin, R., Zhang, H., Lin, Q.-Q., Yang, L.-N., Zhang, K.-F., et al. (2011). The Effects of Buyang Huanwu Decoction on Hemorheological Disorders and Energy Metabolism in Rats with Coronary Heart Disease. J. Ethnopharmacol. 137, 214-220. doi:10.1016/j.jep.2011.05.008

Wang, X. F., and Shi, X. (2015). Clinical Observation on Yixintongmai Granule in Treating Angina Pectoris of Coronary Heart Disease with Qi Deficiency and Blood Stasis Syndrome. Shanxi J. Tradit Chin. Med. 31, 33-35. doi:10.3969/ j.issn.1000-7156.2015.12.017

Wang, X. P. (2016). International Development of New Cardiovascular Medicines. Chin. J. New Drugs 25, 1726-1732. doi:10.1088/0964-1726/ 25/9/095018

Wang, Y.-H., Hong, Y.-L., Feng, Y., Xu, D.-S., Liang, S., Lin, X., et al. (2012). Comparative Pharmacokinetics of Senkyunolide I in a Rat Model of Migraine versus normal Controls. Eur. J. Drug Metab. Pharmacokinet. 37, 91-97. doi:10.1007/s13318-011-0073-6

Wang, Y. J., Zhu, H. Z., Tong, J. B., and Li, Z. G. (2016). Ligustrazine Improves Blood Circulation by Suppressing Platelet Activation in a Rat Model of Allergic Asthma. Environ. Toxicol. Pharmacol. 45, 334-339. doi:10.1016/ j.etap. 2016.06 .016

Wang, Y. X., Li, J. R., and Shen, H. (2005). Experimental Study on Anti Myocardial Ischemia Effect of Guanxin'an Oral Liquid. Chin. J. Exp. Tradit Med. Form 1, 52-54. doi:10.13422/j.cnki.syfjx.2005.01.024

Wei, L. C. (2020). Effect of NF- $\kappa B$ on the Proliferation and Apoptosis of Vascular Smooth Muscle Cells and Related Mechanisms. Zhenjiang: Jiangsu University. master.

Wei, L. C., and Wu, M. (2020). Effect of Overexpression of NF- $\mathrm{kB}$ on Proliferation and Apoptosis of Vascular Smooth Muscle Cells. J. Med. Res. 49, 132-136. doi:10.11969/j.issn.1673-548X.2020.08.031
Wei, Y. Y. (2021). Effect of Clopidogrel Bisulfate on Patients with Coronary Heart Disease and Angina Pectoris. Conti Med. Edu 35, 166-167. doi:10.3969/ j.issn.1004-6763.2021.03.089

Wen, Y. Q., Chen, Y., Li, G., Luo, L., and Chen, P. P. (2019). Analysisof the Current Situation of Chuanxiong Patent protection in china. Pharm. Clin. Chin. Mater. Med. 10, 1-4. CNKI:SUN:LCZY.0.2019-Z1-002.

Wong, K.-L., Chan, P., Huang, W.-C., Yang, T.-L., Liu, I. M., Lai, T.-Y., et al. (2003). Effect of Tetramethylpyrazine on Potassium Channels to Lower Calcium Concentration in Cultured Aortic Smooth Muscle Cells. Clin. Exp. Pharmacol. Physiol. 30, 793-798. doi:10.1046/j.1440-1681.2003.03913.x

Wong, K.-L., Wu, K.-C., Wu, R. S.-C., Chou, Y.-H., Cheng, T.-H., and Hong, H.-J. (2007). Tetramethylpyrazine Inhibits Angiotensin II-Increased NAD(P)H Oxidase Activity and Subsequent Proliferation in Rat Aortic Smooth Muscle Cells. Am. J. Chin. Med. 35, 1021-1035. doi:10.1142/s0192415x0700548x

Wu, C., Chiou, W., and Yen, M. (1989). A Possible Mechanism of Action of Tetramethylpyrazine on Vascular Smooth Muscle in Rat Aorta. Eur. J. Pharmacol. 169, 189-195. doi:10.1016/0014-2999(89)90015-0

Wu, H.-J., Hao, J., Wang, S.-Q., Jin, B.-L., and Chen, X.-B. (2012). Protective Effects of Ligustrazine on TNF- $\alpha$-Induced Endothelial Dysfunction. Eur. J. Pharmacol. 674, 365-369. doi:10.1016/j.ejphar.2011.10.046

Wu, H. Y., and Wang, Y. (2020). Effect of Xiao Xumingtang Combined with Ultraacupuncture along Governor Meridian on Autophagy-Related Protein NF- $\kappa B$ P65 in Cerebral Ischemia Reperfusion Model. Chin. J. Exp. Tradit Med. Form 26, 30-35. doi:10.13422/j.cnki.syfjx.20201606

Wu, T. H., Yin, F., Kong, H. M., and Peng, J. (2019). Germacrone Attenuates Cerebral Ischemia/reperfusion Injury in Rats via Antioxidative and Antiapoptotic Mechanisms. J. Cel Biochem 120, 18901-18909. doi:10.1002/jcb.29210

Wu, T. M., Chen, J. S., and Zeng, X. Y. (2013). Effect of Ruanmailing Oral Liquid on Angiogenesis in Atherosclerotic Plaque of Apoliporotein E Gene Knock-Out Mice. Chin. J. Info Tradit Chin. Med. 20, 37-39. doi:10.3969/j.issn.10055304.2013.09.013

Xia, Q., Bao, Q., Jiang, D. J., and Yi, H. (2018). Evaluation of Embryotoxicity of Chuanxiong Rhizoma Decoction Based on Mouse Embryonic Stem Cell Test Model. Chin. Tradi Pat Med. 40, 1910-1915. doi:10.3696/j.issn.10011528.2018.09.003

Xiao, G. X., Lyu, M., Li, Z. X., Cao, L. H., Liu, X. Y., Wang, Y. L., et al. (2021). Restoration of Early Deficiency of Axonal Guidance Signaling by Guanxinning Injection as a Novel Therapeutic Option for Acute Ischemic Stroke. Pharmacol. Res. 165, 105460. doi:10.1016/j.phrs.2021.105460

Xin, L. Y., Gao, J. L., Lin, H. C., Qu, Y., Shang, C., Wang, Y. L., et al. (2020). Regulatory Mechanisms of Baicalin in Cardiovascular Diseases: A Review. Front. Pharmacol. 11, 583200. doi:10.3389/fphar.2020.583200

Xing, X. Y. (2002). 40 Cases of Hyperlipidemia Treated with Fangfeng Tongsheng Powder. J. New Chin. Med 5, 58. doi:10.3969/j.issn.0256-7415.2002.05.03

Xiuya, Y., Shoufeng, J., Mingming, Q., Wenfeng, H., Bo, Y., and Dan, L. (2020). Vanillic Acid Alleviates Acute Myocardial Hypoxia/Reoxygenation Injury by Inhibiting Oxidative Stress. Oxid. Med. Cel. Longev. 2020, 20208348035. doi:10.1155/2020/8348035

Xu, C. C., Wang, W. W., Wang, B., Zhang, T., Cui, X. M., Pu, Y. Q., et al. (2019). Analytical Methods and Biological Activities of Panax Notoginseng Saponins: Recent Trends. J. Ethnopharmacol. 236, 443-465. doi:10.1016/j.jep.2019.02.035

Xu, L. C., and Li, G. H. (2019). Effect of Ligustrazine on Platelet Activation and Gelsolin Level in ACS Patients after PCI. Anhui Med. J. 40, 775-777. doi:10.3969/j.issn.1000-0399.2019.07.016

Xu, P. (2007). Effect of Zhengxintai Tablet on Angina Pectoris of Coronary Heart Disease. Chin. Comm. Doc 24, 131.

Xuesong, F., Enshi, W., Jianxun, H., Lei, Z., Xiaoli, Z., Yuan, G., et al. (2019). Ligustrazine Protects Homocysteine-Induced Apoptosis in Human Umbilical Vein Endothelial Cells by Modulating Mitochondrial Dysfunction. J. Cardiovasc. Transl. Res. 12, 591-599. doi:10.1007/s12265-019-09900-6

Ya-Xian, W., Ying-Ying, W., Zhiqi, G., Dan, C., Gang, L., Binbin, W., et al. (2021). Ethyl Ferulate Protects against Lipopolysaccharide-Induced Acute Lung Injury by Activating AMPK/Nrf2 Signaling Pathway. Acta Pharmacol. Sin 42, 2069-2081. doi:10.1038/s41401-021-00742-0

Yan, X. J. (2013). Neuroprotective Mechanism of Butylphthalide Injection Pretreatment through the PI3-k/AKt Signaling Pathway in Cerebral Ischemia Reperfusion Injuryon Sprague-Dawley Rats. Dalian: Dalian medical university. master. 
Yan, X. R., Ding, Y. D., Li, S. L., Yang, D. D., He, X. H., and Jiang, W. W. (2020). Study on Mechanism for Treating Hypertension of Ligusticum Chuanxiong Hort. Based on Network Pharmacology. Chin. J. Ethnomed. Ethnopharm. 29, 18-24. CNKI:SUN:MZMJ.0.2020-14-004.

Yang, D. K. (2020a). Dabu Decoction Combined with Nitroglycerin in the Treatment of Heart Failure after Acute Myocardial Infarction. Syst. Med. 5, 115-117. doi:10.19368/j.cnki.2096-1782.2020.12.115

Yang, J. F., Wang, R., Cheng, X. H., Qu, H. C., Qi, J., Li, D., et al. (2020a). The Vascular Dilatation Induced by Hydroxysafflor Yellow A (HSYA) on Rat Mesenteric Artery through TRPV4-dependent Calcium Influx in Endothelial Cells. J. Ethnopharmacol. 256, 112790. doi:10.1016/j.jep.2020.112790

Yang, M. J., Liu, F. W., Zhang, L. Q., Qin, R., Gong, Y. Q., Feng, S. L., et al. (2013). Annual Cultivation Techniques of Ligusticum Chuanxiong in Kunming. Yunnan Agri Sci. Technolo (2), 45. doi:10.3969/j.issn.1000-0488.2013.02.018

Yang, S. L., Huang, L., Liu, Y. J., and Tan, Q. (2020b). Effect of Chaihu Shugan Powder on Acute Myocardial Infarction of Qi Stagnation Cardiothoracic Type and its Influence on H-FABP Level of Patients. Acta Chin. Med. Pharm. 48, 29-33. doi:10.19664/j.cnki.1002-2392.200064

Yang, X. D. (2020b). Clinical Analysis of Tongqiao Huoxue Decoction in the Treatment of Acute Cerebral Infarction. Psychologies 15, 221. doi:10.19738/ j.cnki.psy.2020.01.204

Yang, Y., and Shanshan, P. (2015). Latest Advances in the Research on the Influence of Reactive Oxygen Species-Mediated Oxidative Stress on Myocardial Mitochondria and Autophagy in Cardiovascular Stress and Exercise. China Sport Sci. 35, 71-77+97. doi:10.16469/j.css.201505010

Ye, L., Zhang, Q., Hu, Y., Huang, Y. P., and Liu, Z. (2013). Protective Effects of Xuemaitong Capsule on Rats with Acute Myocardial Infarction and its Mechanism. J. Chongqing Med. Univ. 38, 1433-1437. doi:10.11699/cyxb20131209

Yi, T., Leung, K. S.-Y., Lu, G.-H., Chan, K., and Zhang, H. (2006). Simultaneous Qualitative and Quantitative Analyses of the Major Constituents in the Rhizome of Ligusticum Chuanxiong Using HPLC-DAD-MS. Chem. Pharm. Bull. (Tokyo) 54, 255-259. doi:10.1248/cpb.54.255

Yin, L. (2013). Study on the Chuanxiong Quality Evaluation Based on the Evolution of Origin. Chengdu: Chengdu University of Traditional Chinese Medicine. master.

Yin, M. L. (2018). Clinical Effect of Niuhuang Jiangya Pill in the Treatment of Essential Hypertension. Inner Mongolia J. Tradit Chin. Med. 37, 20-21. doi:10.3969/j.issn.1006-0979.2018.02.016

Yu, J. (2017). List of Pharmaceutical and Food Homologous Raw Materials (2017 Edition). Oral Care Ind. 27, 24-28. doi:10.3969/j.issn.2095-3607.2017.06.007

Yu, R. Y., Guo, Y. Q., and Lin, L. L. (2017). Protective Effects of Ligusticum Wallichii Extract on Cerebral Ischemia and the Correlation Study with NF- $\kappa B$ Pathway. J. Nanjing Univ. Tradit Chin. Med. 33, 74-77. doi:10.14148/ j.issn.1672-0482.2017.0074

Yuan, R., Shi, W. L., Xin, Q. Q., Yang, B. R., Hoi, M. P., Lee, S. M., et al. (2018). Tetramethylpyrazine and Paeoniflorin Inhibit Oxidized LDL-Induced Angiogenesis in Human Umbilical Vein Endothelial Cells via VEGF and Notch Pathways. Evid Based. Complement. Altern. Med. : eCAM 2018, 3082507. doi: $10.1155 / 2018 / 3082507$

Zeng, M. F., Pan, L. M., Qi, S. M., Cao, Y. T., Zhu, H. X., Guo, L. W., et al. (2013). Systematic Review of Recent Advances in Pharmacokinetics of Four Classical Chinese Medicines Used for the Treatment of Cerebrovascular Disease. Fitoterapia 88, 50-75. doi:10.1016/j.fitote.2013.04.006

Zhang, B., Wu, W. J., Zhong, Z. J., Qian, C. Z., Wang, S., Chen, Y., et al. (2018a). Impact of Danshen Ligustrazin for Injection on Neurological Function, Cerebral Edema and Neuronal Apoptosis in Rats with Cerebral Hemorrhage. Pract. J. Card. Cereb Pneumal Vasc. Dis 26, 62-66. doi:10.3969/j.issn.1008-5971.2018.11.015

Zhang, D. Y. (2011). The Study on Separation,purrification and Structure Analysis of the Polysaccharide from the Ligusticum Chuanxiong Hort. Changchun: Northeast Normal University. master.

Zhang, H., Tang, W. W., Wang, S., Zhang, J. H., and Fan, X. (2020a). Tetramethylpyrazine Inhibits Platelet Adhesion and Inflammatory Response in Vascular Endothelial Cells by Inhibiting P38 MAPK and NF- $\kappa$ B Signaling Pathways. Inflammation 43, 286-297. doi:10.1007/s10753-019-01119-6

Zhang, J. F., and Qi, B. K. (2015). Clinical Analysis of 89 Cases of Angina Pectoris of Chronic Coronary Heart Disease Treated with Zhengxintai Capsule. Qinghai Med. J. 6, 56-57.
Zhang, J. J. (2019). Objective to Analyze the Clinical Efficacy of Salvia Miltiorrhiza Ligustrazine Injection in the Treatment of Heart Failure. Chin. J. Mod. Drug Appl. 13, 95-96. doi:10.14164/j.cnki.cn11-5581/r.2019.07.052

Zhang, L. J. (2014). The Research of Pilot-Scale Production,toxicological and Pharmacological of Chuanxiong Volatile Oil Soft Capsule. Shanghai: Second Military Medical University. master.

Zhang, L., Zhou, X., Lu, T. T., Mu, C. L., Wang, X. L., Tang, L. J., et al. (2019). Optimization of Extraction Process of Volatile Oil from Ligusticum Chuanxiong and GC-MS Analysis of its Overground Part. J. Chin. Med. Mater. 42, 607-611. doi:10.13863/j.issn1001-4454.2019.03.029

Zhang, M. S., Gao, F., Teng, F. M., and Zhang, C. B. (2014). Tetramethylpyrazine Promotes the Proliferation and Migration of Brain Endothelial Cells. Mol. Med. Rep. 10, 29-32. doi:10.3892/mmr.2014.2169

Zhang, Q., Yang, Y.-X., Li, S.-Y., Wang, Y.-L., Yang, F.-Q., Chen, H., et al. (2017). An Ultrafiltration and High Performance Liquid Chromatography Coupled with Diode Array Detector and Mass Spectrometry Approach for Screening and Characterizing Thrombin Inhibitors from Rhizoma Chuanxiong. J. Chromatogr. B Analyt Technol. Biomed. Life Sci. 1061-1062, 421-429. doi:10.1016/j.jchromb.2017.07.050

Zhang, X., Han, B., Feng, Z.-M., Yang, Y.-N., Jiang, J.-S., and Zhang, P.-C. (2018b). Ferulic Acid Derivatives from Ligusticum Chuanxiong. Fitoterapia 125, 147-154. doi:10.1016/j.fitote.2018.01.005

Zhang, X. J., Zhang, Y. L., and Zuo, D. D. (2020b). Research Progress on Chemical Constituents and Pharmacological Effects of Ligusticum Chuanxiong Hort. Inf. Tradit Chin. Med. 37, 128-133. doi:10.19656/j.cnki.1002-2406.200177

Zhang, X. L., and Gao, Z. W. (2019). Clinical Study on Shuxin Tongmai Capsules Combined with Atorvastatin in Treatment of Coronary Heart Disease. Drugs \& Clinic 34, 2306-2310. doi:10.7501/j.issn.1674-5515.2019.08.012

Zhang, Z. J., Kong, S. Y., Zhou, D., and He, L. (2006). Effect of Dachuanxiongwan on the Expression of Vascular Epithelial Growth Factor in Rats with Cerebral Ischemia. J. Sichuan Univ. Med. Sci. 37, 246-249. doi:10.3969/j.issn.1672173X.2006.02.021

Zhao, C. (2020). Clinical Evaluation of Taoren Chuanxiong Decoction in Treating 45 Cases of Cerebral Hemorrhage Sequelae. Chin. Pract. Med. 15, 134-136. doi:10.14163/j.cnki.11-5547/r.2020.11.060

Zhao, Y., Lu, L. D., and Zhen, X. H. (2017). The Effect of Ligusticum Chuanxiong Polysaccharide on the Cerebral Ischemia-Reperfusion Injury and the Expression of High Mobility Group Protein B1 in Rats. Chin. J. Gerontol. 37, 2878-2880. doi:10.3969/j.issn.1005-9202.2017.12.007

Zhao, Z. F., Zheng, B., Li, J. H., Wei, Z. H., Chu, S. J., Han, X., et al. (2020). Influence of Crocetin, a Natural Carotenoid Dicarboxylic Acid in Saffron, on L-type Ca Current, Intracellular Ca Handling and Contraction of Isolated Rat Cardiomyocytes. Biol. Pharm. Bull. 43, 1367-1374. doi:10.1248/bpb.b20-00298

Zhao-, X. W., Xu, W. H., Zhao, Y., Wu, Y. H., Luo, W., Zhu, Z. M., et al. (2019). Action Mechanisms of Chuanxiong Rhizoma in Treating Coronary Heart Disease Based on Network Pharmacology. Chin. Tradi Pat Med. 41, 2096-2101. doi:10.3969/j.issn.1001-1528.2019.09.015

Zheng, J. R., and Deng, J. L. (2020). Research Progress in Animal Models of Cerebral Hemorrhage. Med. Recapitulate 26, 960-964. doi:10.3969/j.issn.10062084.2020.05.025

Zheng, Q., Tang, Y., Hu, P.-Y., Liu, D., Zhang, D. L., Yue, P. F., et al. (2018). The Influence and Mechanism of Ligustilide, Senkyunolide I, and Senkyunolide A on Echinacoside Transport through MDCK-MDR1 Cells as Blood-Brain Barrier In Vitro Model. Phytotherapy Res. : PTR 32, 426-435. doi:10.1002/ ptr.5985

Zhi-Gang, Z., Xiao-Lan, Z., Xian-Yue, W., Zhu-Rong, L., and Jing-Chun, S. (2015). Inhibition of Acid Sensing Ion Channel by Ligustrazine on Angina Model in Rat. Am. J. Transl. Res. 7, 1798-1811.

Zhou, M. G., Wang, H. D., Zeng, X. Y., Yin, P., Zhu, J., Chen, W. Q., et al. (2019a). Mortality, Morbidity, and Risk Factors in China and its Provinces, 1990-2017: a Systematic Analysis for the Global Burden of Disease Study 2017. Lancet (London, England) 394, 1145-1158. doi:10.1016/S0140-6736(19)30427-1

Zhou, Y., Ming, J. H., Li, Y. M., Deng, M., Chen, Q., Ma, Y. G., et al. (2019b). Ligustilide Attenuates Nitric Oxide-Induced Apoptosis in Rat Chondrocytes and Cartilage Degradation via Inhibiting JNK and P38 MAPK Pathways. J. Cel. Mol. Med. 23, 3357-3368. doi:10.1111/jcmm.14226

Zhou, Y., Xie, M., Song, Y., Wang, W. P., Zhao, H. R., Tian, Y., et al. (2016). Two Traditional Chinese Medicines Curcumae Radix and Curcumae Rhizoma: An 
Ethnopharmacology, Phytochemistry, and Pharmacology Review. Evid Based. Complement. Altern. Med. : eCAM 2016, 4973128. doi:10.1155/2016/4973128

Zou, J., Chen, G.-D., Zhao, H., Huang, Y., Luo, X., Xu, W., et al. (2018). Triligustilides A and B: Two Pairs of Phthalide Trimers from Angelica Sinensis with a Complex Polycyclic Skeleton and Their Activities. Org. Lett. 20, 884-887. doi:10.1021/acs.orglett.8b00017

Zuo, B. T., Qu, Y. Q., Wang, L. G., Li, L., Zhang, H., and Yang, X. J. (2020). Clinical Study on Xingnao Zhitan Capsule in the Treatment of Carotid Atherosclerosis in Patients with Aacute Cerebral Infarction. Res. Pract. Chin. Med. 34, 73-77. doi:10.13728/j.1673-6427.2020.01.016

Conflict of Interest: The authors declare that the research was conducted in the absence of any commercial or financial relationships that could be construed as a potential conflict of interest.
Publisher's Note: All claims expressed in this article are solely those of the authors and do not necessarily represent those of their affiliated organizations, or those of the publisher, the editors, and the reviewers. Any product that may be evaluated in this article, or claim that may be made by its manufacturer, is not guaranteed or endorsed by the publisher.

Copyright $\odot 2022$ Li, Long, Yu, Shi, Wan, Wen, Li, Liu, Zhang, Li, Zheng, Yang and Shen. This is an open-access article distributed under the terms of the Creative Commons Attribution License (CC BY). The use, distribution or reproduction in other forums is permitted, provided the original author(s) and the copyright owner(s) are credited and that the original publication in this journal is cited, in accordance with accepted academic practice. No use, distribution or reproduction is permitted which does not comply with these terms. 